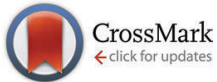

Cite this: New J. Chem., 2015, 39, 9504

Received (in Montpellier, France) 9th June 2015,

Accepted 9th September 2015

DOI: $10.1039 / c 5 n j 01434 d$

www.rsc.org/njc

\title{
Multi-nuclear NMR of axially chiral biaryls in polypeptide orienting solvents: spectral discriminations and enantiorecognition mechanisms $\dagger$
}

\author{
Philippe Berdagué, ${ }^{a}$ Jose-Enrique Herbert-Pucheta, ${ }^{a}$ Vishwajeet Jha, ${ }^{b}$ \\ Armen Panossian, ${ }^{b}$ Frédéric R. Leroux ${ }^{\mathrm{b}}$ and Philippe Lesot*a
} \begin{abstract}
synthesis, as well as their structural role in bioactive natural products, continuous efforts have been undertaken to propose efficient methods for their atropo-selective synthesis. As a consequence, proposing robust and reliable analytical tools that are able to discriminate the spectral signal of atropisomeric enantiomers becomes crucial to evaluate the enantiomeric excesses of mixtures. In this work, we show how several multi-nuclear 1D/2D-NMR techniques using homopolypeptide chiral liquid crystals as aligning solvents can provide a panel of analytical possibilities (through differences of chemical shift anisotropies, dipolar and quadrupolar residual couplings) to spectrally discriminate enantiomers of a large collection of
trisubstituted axially chiral biphenyls. Approaches involving ${ }^{31} \mathrm{P},{ }^{13} \mathrm{C}$ and ${ }^{2} \mathrm{H} 1 \mathrm{D}$ - or 2D-NMR experiments dipolar and quadrupolar residual couplings) to spectrally discriminate enantiomers of a large collection of
trisubstituted axially chiral biphenyls. Approaches involving ${ }^{31} \mathrm{P},{ }^{13} \mathrm{C}$ and ${ }^{2} \mathrm{H} 1 \mathrm{D}$ - or 2D-NMR experiments at natural abundance levels are explored. Among noteworthy results, the first examples of spectral enantioseparations using ${ }^{31} \mathrm{P}$ nuclei as nuclear probe are reported. Finally, the roles of electronic factors and shape anisotropy in the efficiency of chiral discrimination mechanisms are examined and discussed.
Molecular modeling calculations were carried out to establish the electronic profile of these analytes in and shape anisotropy in the efficiency of chiral discrimination mechanisms are examined and discussed.
Molecular modeling calculations were carried out to establish the electronic profile of these analytes in order to understand and rationalize the ${ }^{13} \mathrm{C}-\left\{{ }^{1} \mathrm{H}\right\}$ NMR results.
\end{abstract}

Due to the importance of axially chiral biaryl derivatives as chiral auxiliaries and/or ligands for asymmetric

\section{Introduction}

Axially chiral biaryl derivatives possess a peculiar stereochemical motif able to generate a couple of stereoisomers. The stereogenic structural motif is present in various potentially bioactive natural compounds and exhibits a wide range of biological properties. ${ }^{1}$ For instance, one can mention the well-known vancomycin (a clinically used antibiotic glycopeptide) ${ }^{2}$ or steganacin (a cytotoxic tubulin-binding dibenzocyclooctadiene lignan). ${ }^{3}$ In fact, the biaryl scaffold is a privileged structure for pharmaceutical research as its incorporation assures frequently high entry rates. ${ }^{4}$

\footnotetext{
${ }^{a}$ Laboratoire de RMN en Milieu Orienté, Institut de Chimie Moléculaire et des Matériaux d'Orsay (ICMMO), UMR CNRS 8182,

Université Paris-Sud, Université Paris-Saclay, 91405 Orsay, France.

E-mail: philippe.lesot@u-psud.fr; Fax: +33 (0)1 691581 05;

Tel: +33 (0)1 69154759

${ }^{b}$ Laboratoire de Chimie Moléculaire, Université de Strasbourg, UMR CNRS 7509, ECPM, 25 Rue Becquerel, 67087 Strasbourg, France

$\dagger$ Electronic supplementary information (ESI) available: A description of experimental details and DFT calculation, analytical details, chemical pathway, background of NMR in CLC, further 1D/2D NMR spectra, and NMR assignment data of compound 16 are given. Composition of oriented samples, details on anisotropic NAD NMR, further anisotropic NMR spectra and extra discussion for some compounds. See DOI: 10.1039/c5nj01434d
}

In addition, the stereogenic axes provide rigid molecular frameworks for highly efficient tools in asymmetric synthesis. ${ }^{5}$ Concomitantly, atropisomeric $C_{1}$-symmetric biaryls play an important and effective role as chiral auxiliaries and/or ligands for asymmetric synthesis. Consequently, continuous efforts have been undertaken by organic chemists to develop efficient methods for the atropo-selective synthesis of ligands based on the biphenyl, binaphthyl, or other biaryl backbones. ${ }^{6}$ The conformational stability of bridged biaryls can be strongly increased by incorporation of ortho-substituents, the associated rotational energy barrier primary depending on their number and their bulkiness. ${ }^{7}$ Generally, ortho-trisubstituted biphenyls show no stereo-labile properties, and hence no rapid enantiomerization at room temperature is expected (see Fig. 1a). ${ }^{8}$

So far, both chiral supercritical fluid chromatography and chiral gas chromatography have been the main methods used to separate the enantiomers of such peculiar chiral compounds. ${ }^{8,9}$ Although adequate in numerous cases, chromatographic approaches present some well-known specific drawbacks for systematic implementation (price of chiral columns, for instance). Furthermore, the determination of experimental conditions leading to enantiomeric resolution is sometimes highly timeconsuming. As a consequence, proposing (simple) analytical 
(a)

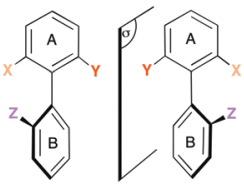

(b)

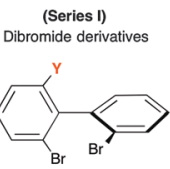

$1(S): Y=1$

$2(R): Y=\mathrm{COOH}$

$3(R): Y=\mathrm{CHO}$

$4(R): Y=\mathrm{OMe}$
$5(R): Y=\mathrm{Me}$

$6(R): Y=C O O M$

Fig. 1 (a) General structure of enantiomeric couples of ortho-trisubstituted biphenyls investigated here, along with the systematic atomic numbering used. The aromatic cycle B contains the $Z$ substituent and quaternary carbon atoms are displayed in green. (b) Structures of chiral compounds 1 to 17 defined by series: (I): dibromo derivatives (1 to 6); (II): chloro-bromo derivatives (7 to 11); (III): monophosphorous derivatives (12 to 15); (IV): miscellaneous derivatives (16 and 17). The stereodescriptors reported in the four series correspond to structures drawn. As short notation associated to atropisomers, we will use the stereodescriptors $(S / R)$ instead of (aS/aR).

alternatives involving other techniques, such as NMR spectroscopy, to chemists is a valuable task.

In the past, liquid-state NMR methods involving mainly chiral derivatizing agents (MPTA or Mosher's acid) in combination with or without lanthanide shift reagents have been proposed to discriminate enantiomers of (bridged or not) chiral biaryl atropisomers. ${ }^{10}$ Although successful, these approaches require the presence of accessible reactive groups $\left(-\mathrm{COOH},-\mathrm{OH},-\mathrm{NH}_{2}, \ldots\right)$ to generate (in situ or not) diastereoisomers.

This prerequisite can be overcome when using NMR in lyotropic chiral liquid crystals (CLC). This breakthrough approach was revealed to be a powerful and flexible tool, providing a robust and general alternative to the multitude of isotropic NMR methods for the differentiation of enantiomers of chiral molecules, ${ }^{11}$ but also enantiotopic elements in prochiral molecules. ${ }^{12-14}$ Compared to classical NMR approaches using chiral derivatizing or solvating chiral agents, NMR in CLC requests no specific functional groups inside the analyte, ${ }^{15}$ while all magnetically active nuclei (even at very low natural abundance levels) can provide effective probes.

Using a chiral aligned environment, the intermolecular interactions between each enantiomer (or each enantiotopic direction) and the CLC differ, and hence the internuclear vectors, $\mathrm{i}-\mathrm{j}$, are not oriented the same on average, $S_{\mathrm{i}-\mathrm{j}}^{S} \neq S_{\mathrm{i}-\mathrm{j}}^{R}\left(\right.$ or $\left.S_{1-\mathrm{j}}^{\text {pro- } S} \neq S_{1-\mathrm{j}}^{\text {pro- }}\right) .{ }^{11-13} \mathrm{~A}$ doubling of the spectral information/patterns for a given nuclear site indicates therefore that the enantiorecognition phenomenon occurs and is revealed on the NMR spectrum by a difference of residual chemical shift anisotropies (CSA), dipolar couplings (D) or quadrupolar couplings $\left(\Delta \nu_{\mathrm{Q}}\right)$ (for spin $\left.I>1 / 2\right)$ (see Fig. S1, ESI $\dagger) .{ }^{16,17}$ As a first example, deuterium NMR in CLC was used to analyze the intramolecular dynamic processes of chiral and prochiral deuterated ortho-disubstituted biaryls (derivatives of 1-(4-methylphenyl)naphthalene). ${ }^{14}$
In this work, we show how multi-nuclear 1D/2D-NMR using chiral anisotropic solvents (homopolypeptide CLC) can provide various analytical possibilities to spectrally separate enantiomers of a large collection of ortho-trisubstituted axially chiral biphenyls (see Fig. 1). From an analytical viewpoint, anisotropic NMR results will be discussed in terms of spectral enantiodiscrimination efficiency and an attempted rationalization of the results is proposed. For this purpose, the seventeen analytes investigated have been classified into four series of structurally related molecules (I to IV) depending on the similarity of their substitution patterns, as displayed in Fig. $1 \mathrm{~b}$.

\section{Experimental section}

\section{Synthesis}

The synthesis of these atropisomeric biaryls was recently reported using an original, modular approach (see Fig. S2, ESI $\dagger$ ). ${ }^{8}$ Briefly speaking, it is based on (a) the preparation of ortho, ortho' dibromobiphenyls bearing an additional substituent in the 6-position via a transition metal-free aryl-aryl coupling (the 'ARYNE coupling'), ${ }^{18}$ (b) the regioselective introduction of an enantiopure $p$-tolylsulfinyl group as a traceless chiral auxiliary allowing the separation of atropo-diastereoisomers by simple crystallization, (c) the chemoselective functionalization of this auxiliary and (d) subsequent regioselective functionalization of the remaining bromine atoms. During all these chemical transformations, the configuration of the biaryl axis is maintained, and hence no racemization was found to occur. ${ }^{8}$ The diphosphine 16 was obtained by means of catalytic C-P coupling. ${ }^{19}$

\section{Material for oriented NMR samples}

In this study, homopolypeptide CLC samples were composed of poly- $\gamma$-benzyl-L-glutamate (PBLG), purchased from Sigma and dissolved in chloroform. ${ }^{11,20}$ The degree of polymerization of PBLG is equal to 743 ( $\mathrm{MW}=162900 \mathrm{~g} \mathrm{~mol}^{-1}$ ). The mass of solute in the samples varies from 19 to $100 \mathrm{mg}$, while the molar variation ranking from $2.1 \times 10^{-6}$ (sample 14) to $1.8 \times 10^{-4}$ mol per enantiomer (sample 17). Table S1 (ESI $\dagger$ ) lists the exact composition (samples 1 to 17) and if the chloroform was protonated or deuterated. The preparation of (sealed) anisotropic NMR tubes and practical aspects have been reported in previous papers (also see ESI $\dagger$ ). ${ }^{10,12,13}$

\section{NMR spectroscopy}

${ }^{13} \mathrm{C},{ }^{13} \mathrm{C}-\left\{{ }^{1} \mathrm{H}\right\}$ and ${ }^{31} \mathrm{P}-\left\{{ }^{1} \mathrm{H}\right\}$ 1D/2D-NMR spectra were recorded on routine 9.4 $\mathrm{T}$ Bruker (Avance I) NMR spectrometers equipped with either a $5 \mathrm{~mm}$ BBO, TBI or QXO probe. Unless otherwise specified, the sample temperature was set to $298 \mathrm{~K}$. NAD $-\left\{{ }^{1} \mathrm{H}\right\} 2 \mathrm{D}$ NMR spectra were performed on 14.1 T Bruker (Avance II) spectrometer equipped with a $5 \mathrm{~mm}^{2} \mathrm{H}$ selective cryoprobe, ${ }^{17,21}$ and the WALTZ16 CPD sequence was used to decouple proton $(0.5 \mathrm{~W}) .{ }^{11}$ Specific experimental details are given in the figure captions.

\section{Molecular modeling and DFT calculations}

Geometry optimizations and electronic structure determinations were carried out using the Gaussian 09 program running 
on the "IDA" cluster of the University of Paris-Sud. ${ }^{22}$ Density functional theory (DFT) with self-consistent reaction field (SCRF) Tomasi's polarized continuum model (PCM) for solvation ${ }^{23}$ was used in all calculations to describe implicitly the solvent (chloroform) for energy minimizations and for description of orbitals. All computations were performed with the hybrid method B3LYP, whereas electronic correlation and exchange were respectively described by the use of the Becke ${ }^{24}$ and Lee-Yang-Parr ${ }^{25}$ functionals. Relativistic effective core potentials (ECP) were used to describe electrons of heavy atoms $(\mathrm{Br}$ and $\mathrm{Cl})$ with the valence double z quality basis sets Lanl2dz. ${ }^{26}$ The standard 6-311G(d,p) basis sets were used for the rest of the atomic orbitals' descriptions of $\mathrm{H}, \mathrm{C}, \mathrm{O}$ and $\mathrm{P}$ atoms. Local minima conditions per molecule were confirmed with the calculation of harmonic vibrational frequencies of all structures. None of the predicted vibrational spectra has any imaginary frequency (data not shown), implying that the optimized geometry of each of the molecules under study lies at a local point on the potential energy surface. The electronic properties such as Molecular Electrostatic Potential (MEP), frontier molecular HOMO-LUMO orbital energies and Mulliken atomic charges have been obtained with the same level of theory as previously described.

\section{Results and discussion}

For a global view of the results, Table 1 (see also Table S2, ESI $\dagger$ ) summarizes the essential data for the analytes and the sets of experimental results. As all results were obtained with very similar experimental conditions $(T \approx 298 \mathrm{~K}, \mathrm{~W} / \mathrm{W}$ of PBLG of $14 \%$ ), we will then follow with their interpretation in terms of chiral discrimination mechanisms (noted in short as CDMs). In particular, for the ${ }^{13} \mathrm{C}$ NMR results, attempts to correlate the number of ${ }^{13} \mathrm{C}$ discriminated sites (noted in short as $\operatorname{NDS}\left({ }^{13} \mathrm{C}\right)$ ) and the possible solute-PBLG electrostatic interactions in combination with molecular shape recognition effects will be proposed and discussed.

\section{${ }^{1}$ H 1D-NMR spectroscopy}

Even for small-size molecules, the number and the magnitude of (short and long-range) ${ }^{1} \mathrm{H}-{ }^{1} \mathrm{H}$ residual dipolar couplings significantly increase the linewidth to obtain rather low-resolution ${ }^{1} \mathrm{H}$ spectra where no fine structures clearly emerge. Some exceptions can be found with molecules possessing isolated methyl groups, for instance. Compounds 4 to 6, 10, 11 and 17 are typical examples. Contrarily to isotropic ${ }^{1} \mathrm{H}$ NMR, an uncoupled methyl group exhibits a triplet structure in a LC (instead of a single resonance) due to the intramethyl ${ }^{1} \mathrm{H}-{ }^{1} \mathrm{H}$ dipolar couplings (see Fig. S3, ESI $\dagger$ ). In a CLC, two triplets with different splittings $\left(\left|3 D_{\mathrm{HH}}^{S}\right| \neq\left|3 D_{\mathrm{HH}}^{R}\right|\right)$ centered on very close ${ }^{1} \mathrm{H}$ chemical shifts (due to a small difference of ${ }^{1} \mathrm{H}$ CSA) are generally detected.

For analytes, 6 and 11, a single triplet (with $\left|3 D_{\mathrm{HH}}\right|=58$ and $52 \mathrm{~Hz}$, respectively) is observed, thus revealing no resolved discrimination through a difference of $D_{\mathrm{HH}}$. Two reasons may explain this absence of enantiodiscriminations: (i) the rather low sensitivity of $D\left({ }^{1} \mathrm{H}-{ }^{1} \mathrm{H}\right)$ to a difference of orientational ordering (compared to ${ }^{2} \mathrm{H}$ quadrupolar interaction, for instance); (ii) the complex conformational dynamics of ligand Y (here, up to three rotors), which generally leads to averaging down the order parameters of each internuclear vector along the chain, and subsequently reduces spectral enantiodifferences. For solutes 5, 10 and 17, a symmetric ${ }^{1} \mathrm{H}$ spectral pattern of six lines is observed for methyl bound to the ring (see Fig. S3, ESI $\dagger$ ). This structure can be analyzed as follows: (i) a dedoubled triplet if the methyl group is dipolarly coupled with one of the aromatic protons; (ii) two triplets centered on two ${ }^{1} \mathrm{H}$ chemical shifts due to a surprisingly large ${ }^{1} \mathrm{H}$ CSA. Two approaches involving the components of mixture can be proposed to assess the origin of the spectral pattern. They consist of either recording the

Table 1 Compilation of various solute parameters and the associated number of discriminated sites (racemic series) using proton-decoupled ${ }^{2} \mathrm{H}$, ${ }^{13} \mathrm{C}$ and ${ }^{31} \mathrm{P}$ NMR results in PBLG

\begin{tabular}{|c|c|c|c|c|c|c|c|c|c|}
\hline Series & Solute & $\begin{array}{l}\text { Mass } \\
(\mathrm{mg})\end{array}$ & $10^{-5} \times n^{R \text { or } S} / \mathrm{mole}$ & 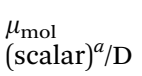 & $\begin{array}{l}\text { Hydrogen } \\
\text { bond }\end{array}$ & $\begin{array}{l}\text { Oxygen } \\
\text { atom }\end{array}$ & $\begin{array}{l}{ }^{13} \mathrm{C}-\left\{{ }^{1} \mathrm{H}\right\}^{b} \\
\text { NMR }\end{array}$ & $\begin{array}{l}{ }^{2} \mathrm{H}-\left\{{ }^{1} \mathrm{H}\right\}^{b} \\
\text { NMR }\end{array}$ & $\begin{array}{l}{ }^{31} \mathrm{P}-\left\{{ }^{1} \mathrm{H}\right\}^{b} \\
\text { NMR }\end{array}$ \\
\hline \multirow[t]{6}{*}{$\mathrm{I}(\mathrm{Br} / \mathrm{Br})$} & $1(\mathrm{I})$ & 19.9 & 2.27 & 2.132 & $\mathrm{~N}$ & $\mathrm{~N}$ & $1 / 12$ & $\mu^{c}$ & - \\
\hline & $2(\mathrm{COOH})$ & 54.5 & 7.65 & 2.529 & $\mathrm{Y}$ & $\mathrm{Y}$ & $12 / 13$ & $\mathrm{US}^{d}$ & - \\
\hline & $3(\mathrm{CHO})$ & 61.0 & 9.00 & 2.933 & $\mathrm{~N}$ & $\mathrm{Y}$ & $9 / 13$ & $7 / 8^{e}$ & - \\
\hline & 4 (OMe) & 100.0 & 14.60 & 4.213 & $\mathrm{~N}$ & $\mathrm{Y}$ & $10 / 13$ & $7 / 8^{e}$ & - \\
\hline & $5(\mathrm{Me})$ & 21.2 & 3.25 & 3.104 & $\mathrm{~N}$ & $\mathrm{~N}$ & $6 / 13$ & NS & - \\
\hline & 6 (COOMe) & 72.2 & 9.75 & 2.963 & $\mathrm{~N}$ & $\mathrm{Y}$ & $8 / 13$ & $6 / 8$ & - \\
\hline \multirow[t]{5}{*}{ II $(\mathrm{Cl} / \mathrm{Br})$} & 7 (I) & 21.1 & 2.68 & 2.213 & $\mathrm{~N}$ & $\mathrm{~N}$ & $3 / 12$ & / & - \\
\hline & $8(\mathrm{COOH})$ & 59.5 & 9.55 & 2.357 & $\mathrm{Y}$ & $\mathrm{Y}$ & $11 / 13$ & US & - \\
\hline & $9(\mathrm{CHO})$ & 62.6 & 10.60 & 2.737 & $\mathrm{~N}$ & $\mathrm{Y}$ & $11 / 13$ & $6 / 8^{e}$ & - \\
\hline & $10(\mathrm{Me})$ & 19.0 & 3.38 & 3.179 & $\mathrm{~N}$ & $\mathrm{Y}$ & $6 / 13$ & NS & - \\
\hline & 11 (COOMe) & 70.1 & 10.75 & 3.006 & $\mathrm{~N}$ & $\mathrm{Y}$ & $8 / 13$ & $6 / 8$ & - \\
\hline \multirow[t]{4}{*}{ III (Cl/Br) } & $12\left(\mathrm{PPh}_{2}\right)$ & 26.0 & 2.88 & 4.166 & $\mathrm{~N}$ & $\mathrm{~N}$ & $4 / 24^{f}$ & l & $0 / 1$ \\
\hline & $13\left(\mathrm{POPh}_{2}\right)$ & 96.2 & 10.26 & 4.622 & $\mathrm{~N}$ & $\mathrm{Y}$ & $12 / 24^{f}$ & l & $0 / 1$ \\
\hline & $14\left(\mathrm{PCy}_{2}\right)$ & 25.3 & 2.73 & 3.048 & $\mathrm{~N}$ & $\mathrm{~N}$ & $3 / 24^{f}$ & l & $1 / 1$ \\
\hline & $15\left(\mathrm{POCy}_{2}\right)$ & 20.1 & 2.09 & 5.146 & $\mathrm{~N}$ & $\mathrm{Y}$ & $2 / 24^{f}$ & l & $0 / 1$ \\
\hline \multirow[t]{2}{*}{ IV } & $16\left(\mathrm{P}_{2}\right)^{e}$ & 30.4 & 2.73 & 5.290 & $\mathrm{~N}$ & $\mathrm{~N}$ & $12 / 36^{f}$ & / & $2 / 2$ \\
\hline & $17(\mathrm{Me} / \mathrm{OMe})$ & 100.6 & 18.20 & 2.377 & $\mathrm{~N}$ & $\mathrm{~N}$ & $6 / 14$ & $7 / 9^{e}$ & - \\
\hline
\end{tabular}

${ }^{a}$ The molecular electric dipole moment, $\mu_{\text {mol }}$, is calculated for the lowest-energy conformer. ${ }^{b}$ Number of sites $\left({ }^{13} \mathrm{C},{ }^{2} \mathrm{H},{ }^{31} \mathrm{P}\right)$ spectrally discriminated. ${ }^{c}$ /: spectrum not recorded. ${ }^{d}$ US: unexpoitable NAD spectrum. ${ }^{e}$ For one site ${ }^{2} \mathrm{H}$, two interpretations of results are possible. ${ }^{f 13} \mathrm{C}$ signals are also decoupled from ${ }^{31} \mathrm{P}$ signals. 
${ }^{1} \mathrm{H}$ spectrum in ALC made of a racemic mixture of PBLG and PBDG (PBLG's enantiomer) ${ }^{27}$ or using the enantiopure compound (when available) in the CLC. Irrespective of the method used, it appears here that the doubling of triplets has its origin from the dipolar coupling with the ortho-position aromatic proton as simply exemplified in the case of $\mathbf{1 0}$ (see Fig. S1, ESI $\dagger$ ). Spin-manipulation based alternatives for simplifying the coupling pattern of ${ }^{1} \mathrm{H}$ signals should be possible but they are beyond the scope of this paper and have not been explored.

\section{${ }^{1} \mathrm{H}$-(de)coupled ${ }^{31} \mathrm{P}$ NMR spectroscopy}

Compounds 12 to 16 possess ${ }^{31} \mathrm{P}$ nuclei, which are both sensitive and $100 \%$ abundant, and hence easy to detect. Spectral enantiodiscriminations can be observed through the difference of ${ }^{31} \mathrm{P}$ CSA, leading to two independent resonances, one for each enantiomer, or a difference of ${ }^{31} \mathrm{P}^{-1} \mathrm{H}$ RDCs. For the series of monophosphorous derivatives, no exploitable spectral separations based on ${ }^{31} \mathrm{P}-{ }^{1} \mathrm{H}$ RDC differences were obtained on the ${ }^{31} \mathrm{P}$ 1D-NMR spectra, mainly due to the presence of various long-range ${ }^{31} \mathrm{P}-{ }^{1} \mathrm{H}$ RDCs, which obscure spectra. When protons are decoupled, spectra are significantly simplified. Contrarily to 12, 13 and 15, the presence of two ${ }^{31} \mathrm{P}$ resonances for solute $\mathbf{1 4}$ indicates that enantiomers are discriminated on the basis of ${ }^{31} \mathrm{P}$ CSA differences $\left(|\Delta \sigma|=14 \mathrm{~Hz}, \Delta \nu_{1 / 2}=3.5 \mathrm{~Hz}\right)$ (see Fig. 2a). Surprisingly, monophosphine oxide biaryl moieties 13 and 15 are not spectrally discriminated despite the expected increase of the electronic shielding anisotropy of the phosphorous nucleus due to the presence of the oxygen atom, which produces bigger ${ }^{31} \mathrm{P}$ CSA susceptible to lead (a priori) to larger enantiodiscriminations. Variable temperature ${ }^{31} \mathrm{P}$ NMR experiments (range of $30 \mathrm{~K}$ ) did not permit enantiodiscriminations neither for $\mathbf{1 3}$ nor for $\mathbf{1 5}$. The last strongly suggests that the energy gap of the interconversion barrier between enantiomers is importantly increased by

(a)
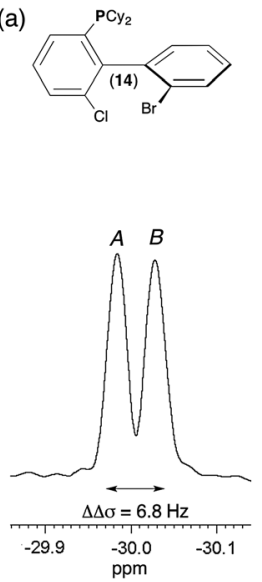

Fig. $2161.9 \mathrm{MHz}{ }^{31} \mathrm{P}-\left\{{ }^{1} \mathrm{H}\right\}$ 1D-NMR spectrum of (a) $(R / S)-14$ in PBLG/ $\mathrm{CHCl}_{3}$ at $335 \mathrm{~K}$ and (b) of 16 in racemic series (bottom) and enantioenriched series ( $R$ isomer) (top) in PBLG/CDCl 3 at $298 \mathrm{~K}$ (ref. $\delta(80 \%$ of $\left.\mathrm{H}_{3} \mathrm{PO}_{4}\right)=0$ ppm). 1000 scans (a) and 5000 scans (b) are added and soft line-sharpened Gaussian filtering is applied. Note the ${ }^{31} \mathrm{P}$ CSA of $3.9 \mathrm{~Hz}$ and $4.5 \mathrm{~Hz}$ for $\mathrm{P}_{A}$ and $\mathrm{P}_{B}$ of 16. The assignment of $\mathrm{P}_{A}$ and $\mathrm{P}_{B}$ atoms is given in $\mathrm{ESI} \dagger$ (see Fig. S14 to S18 in Section SI-SIII). The italicized notations " $A / B^{\prime \prime}$ stand for the chiral stereodescriptors of enantiomers $A$ and $B$. the fact that aryls' free-rotation is sterically hindered by the presence of the oxide and thus only one enantiomer is favored.

Finally, the case of chiral biaryl-based diphosphane $\mathbf{1 6}$ is rather peculiar. Indeed in the liquid state, this molecule possesses two anisochronous ${ }^{31} \mathrm{P}$ atoms (at room temperature) resonating at two distinct chemical shifts $\left(\delta\left({ }^{31} \mathrm{P}_{\mathrm{A}}\right)=-12.0 \mathrm{ppm}\right.$ and $\delta\left({ }^{31} \mathrm{P}_{\mathrm{B}}\right)=$ $-14.1 \mathrm{ppm}$ ) and mutually coupled as first evidenced in $2011 .{ }^{28}$ This spin-spin coupling finds its origin via a "through-space" scalar coupling (noted $J\left({ }^{31} \mathrm{P}_{\mathrm{A}^{-}}{ }^{31} \mathrm{P}_{\mathrm{B}}\right)=22.7 \mathrm{~Hz}$ ) and not via the intramolecular five-bond connectivity, which should lead to a small scalar ${ }^{5} J\left({ }^{31} \mathrm{P}_{\mathrm{A}^{-}}{ }^{31} \mathrm{P}_{\mathrm{B}}\right)$ coupling. The spectral assignments of $\mathrm{P}_{\mathrm{A}}$ and $\mathrm{P}_{\mathrm{B}}$ atoms derive from the analysis of ${ }^{1} \mathrm{H}^{3}{ }^{31} \mathrm{P} 2 \mathrm{D}$ HMBC, ${ }^{31} \mathrm{P}$ 2D J-resolved and ${ }^{1} \mathrm{H}_{-}{ }^{1} \mathrm{H}$ 2D COSY experiments shown in $\mathrm{ESI} \dagger$ (Section SIII). If two doublets (AX spin system) are observed on the isotropic ${ }^{31} \mathrm{P}-\left\{{ }^{1} \mathrm{H}\right\}$ spectrum, four resonances $\left(\Delta \nu_{1 / 2}<0.8 \mathrm{~Hz}\right)$ are detected at each ${ }^{31} \mathrm{P}$ site in a racemic series (see Fig. S2a and S4, ESI $\dagger$ ). This doubling of lines indicates enantiodiscrimination. Three spectral situations corresponding to a difference of either ${ }^{31} \mathrm{P}$ CSA or ${ }^{31} \mathrm{P}-{ }^{31} \mathrm{P}$ RDC or from both contributions can explain the presence of two pairs of doublets for each ${ }^{31} \mathrm{P}$ site (see Fig. S5, ESI $\dagger$ ). The assignment of ${ }^{31} \mathrm{P}$ resonances was assessed by comparing the 1D spectrum of $\mathbf{1 6}$ to the one recorded with an enantioenriched mixture (enriched in $R$ isomer, ee $=51.3 \%$ ) using similar experimental conditions (sample composition and temperature). As seen in Fig. 2b, the peak intensity difference between enantiomers allows their associated signals to be undoubtedly assigned. Various homonuclear 2D experiments confirm qualitatively the presence of each enantiomer, regardless of the absolute configuration of NMR signals (vide infra and ESI $\dagger$ ). According to the enantioassignment made, the analysis of ${ }^{31} \mathrm{P}-\left\{{ }^{1} \mathrm{H}\right\}$ 1D spectrum of $\mathbf{1 6}$ indicates that total couplings between the two ${ }^{31} \mathrm{P}$ nuclei for each isomer, $\left|T^{A}\left({ }^{31} \mathrm{P}^{-}{ }^{31} \mathrm{P}\right)\right|$ and $\left|T^{B}\left({ }^{31} \mathrm{P}-{ }^{31} \mathrm{P}\right)\right|$ with $T=J+2 D$, are very close and equal to 18.7 and $19.1 \mathrm{~Hz}$, respectively while each doublet is shifted by $3.9 \mathrm{~Hz}\left({ }^{31} \mathrm{P}_{\mathrm{A}}\right)$ and $4.5 \mathrm{~Hz}\left({ }^{31} \mathrm{P}_{\mathrm{B}}\right)$. Assuming a negative value for $T^{A}$ or ${ }^{B}$, the magnitude of $D\left({ }^{31} \mathrm{P}-{ }^{31} \mathrm{P}\right)$ is equal to -20.3 and $-20.5 \mathrm{~Hz}$ for $R$ and $S$, respectively. Conversely, if $T\left({ }^{31} \mathrm{P}-{ }^{31} \mathrm{P}\right){ }^{A}$ or ${ }^{B}$ is positive, $D\left({ }^{31} \mathrm{P}-{ }^{31} \mathrm{P}\right)^{A}$ or $B$ becomes equal to -2 or $-1.8 \mathrm{~Hz}$, respectively. Among the two anisotropic contributions (D and CSA), only the ${ }^{31} \mathrm{P} \operatorname{CSA}(\Delta \Delta \sigma=3.9 \mathrm{~Hz}$ and $4.5 \mathrm{~Hz}$ ) is the relevant NMR interaction here that can be in fine efficiently exploited to evaluate the ee. As CSA is directly proportional to the magnetic field strength, operating with higher magnetic field spectrometers should guarantee larger discriminations. Interestingly, the results obtained here are the two first examples of enantiodifferentiation using ${ }^{31} \mathrm{P}-\left\{{ }^{1} \mathrm{H}\right\} \mathrm{NMR}$, so far. Previous studies using ${ }^{31} \mathrm{P}-\left\{{ }^{1} \mathrm{H}\right\}$ or ${ }^{31} \mathrm{P}$ NMR as the analytical technique had failed in discriminating enantiomers of phosphorous compounds. ${ }^{29}$

\section{${ }^{1} \mathrm{H}$-decoupled ${ }^{13} \mathrm{C}$ 1D-NMR}

Although less sensitive compared to ${ }^{1} \mathrm{H}$ or ${ }^{31} \mathrm{P}$ NMR, anisotropic ${ }^{13} \mathrm{C}-\left\{{ }^{1} \mathrm{H}\right\}$ NMR at natural abundance is an excellent and competitive method to discriminate enantiomers, in particular when $\mathrm{sp}^{2}$ hybridized carbon atoms are present in the analyte. The gain in sensitivity of commercially available cryogenic 
probes with respect to conventional ones (up to a factor of 4 to 5) enables the experimental acquisition times of qualitative ${ }^{13} \mathrm{C}-\left\{{ }^{1} \mathrm{H}\right\}$ NMR to be reduced to less than $1-2$ hour(s), ${ }^{30}$ even working with small amounts of solutes or with analytes of high MW. However, when a sufficient amount of solute is available (10-30 mg), depending on the enantiomeric mole number (from $2.27 \times 10^{-5}$ to $18.20 \times 10^{-5}$ ) and the $\mathrm{S} / \mathrm{N}$ ratio $(\mathrm{SNR})$ desired, all ${ }^{13} \mathrm{C}-\left\{{ }^{1} \mathrm{H}\right\}$ 1D spectra were recorded with a moderate magnetic field (9.4 $\mathrm{T}$ ) using acquisition times in the range of 3-10 hours.

All experimental data related to the number of discriminated ${ }^{13} \mathrm{C}$ sites in PBLG are presented in Table 1, while Table S3 $(\mathrm{ESI} \dagger)$ lists the value of all $\delta\left({ }^{13} \mathrm{C}\right)$ and the differences of CSA $(\Delta \Delta \sigma)$ for each of them.

For derivatives of series I and II, the $1 \mathrm{D}$ analysis of ${ }^{13} \mathrm{C}-\left\{{ }^{1} \mathrm{H}\right\}$ NMR spectra in CLC can be easily performed by counting the number of ${ }^{13} \mathrm{C}$ lines and then comparing with the isotropic ${ }^{13} \mathrm{C}-\left\{{ }^{1} \mathrm{H}\right\}$ NMR spectra where no discrimination occurs (see Fig. S6, ESI $\dagger$ ). For all of them, several spectral enantiodiscriminations occur both in the $\mathrm{CH}$ and quaternary aromatic carbon atoms, but the number of differentiated ${ }^{13} \mathrm{C}$ sites varies from one (solute 1) to twelve sites (solute 2), with spectral difference from $1 \mathrm{~Hz}$ (limit of discrimination) to $14 \mathrm{~Hz}$. Note that carbon atoms belonging to the Y substituent (see Fig. 1) can provide further potential ${ }^{13} \mathrm{C}$ sites for discrimination like in the case of 4, 9 and 10, for instance (see Table S3, ESI $\dagger$ ).

Two illustrative examples of ${ }^{13} \mathrm{C}-\left\{{ }^{1} \mathrm{H}\right\}$ 1D spectra (solutes 2 and 8) are given in Fig. 3. The variations of $\delta\left({ }^{13} \mathrm{C}\right)$ between 2 and $\mathbf{8}$ (and between each solute) result in the well-known electronic effects $(+\mathrm{I},-\mathrm{I}$ and $+\mathrm{M},-\mathrm{M})$ of various substituents on the rings (see also Fig. S4, ESI $\dagger$ ). For 2 and 8 , about $90 \%$ of ${ }^{13} \mathrm{C}$ sites are discriminated, thus affording a multiple choice for measuring enantiomeric excess (ee) of mixture. However, from a quantitative viewpoint, the choice of the best sites is clearly governed by three parameters (i) the spectral frequency differences between enantiomer signals; (ii) SNR; and (iii) signal overlapping of analytes with solvent signals. Typically, for 2 and 8 , the C-4 atom ( $\mathrm{SNR} \approx 80-100$ ) provides the best site for quantitative purposes when the $\mathrm{PBLG} / \mathrm{CHCl}_{3}$ chiral system is used. Carbon atom C-9 could also provide a discrimination site but the signal overlay with very broad resonances of PBLG aromatic signals complicates the evaluation of enantiomeric purity. Finally, the quaternary C-6 and C-8 (for 2) or C-6 (for 8) carbons also provide large separations $(\approx 11 \mathrm{~Hz})$, but their low SNR ( $\approx 30-35)$ excludes them from an accurate determination of large ee's. The overall interspectral analysis of all analytes indicates that biaryls with an aldehyde (3 and 9), ether (4) and ester (6 and 11) substituent possess numerous enantiodiscriminated sites (60 to $80 \%$ ), but these sites show smaller spectral differences ( 1 to $3.5 \mathrm{~Hz}$ ).

For methylated biaryls (5 and 10), the ratio of enantiodiscriminated sites does not exceed 50\% while the lowest number of sites $(<25 \%)$ is obtained for the iodo derivatives ( 1 and 7$)$. ${ }^{13} \mathrm{C}-\left\{{ }^{1} \mathrm{H}\right\}$ 1D-NMR spectra of 7 and 9 are given in the ESI. $\dagger$ Similar experimental conditions (co-solvent, w/w of polypeptide and temperature) for all solutes allow ${ }^{13} \mathrm{C}$ spectral comparisons.
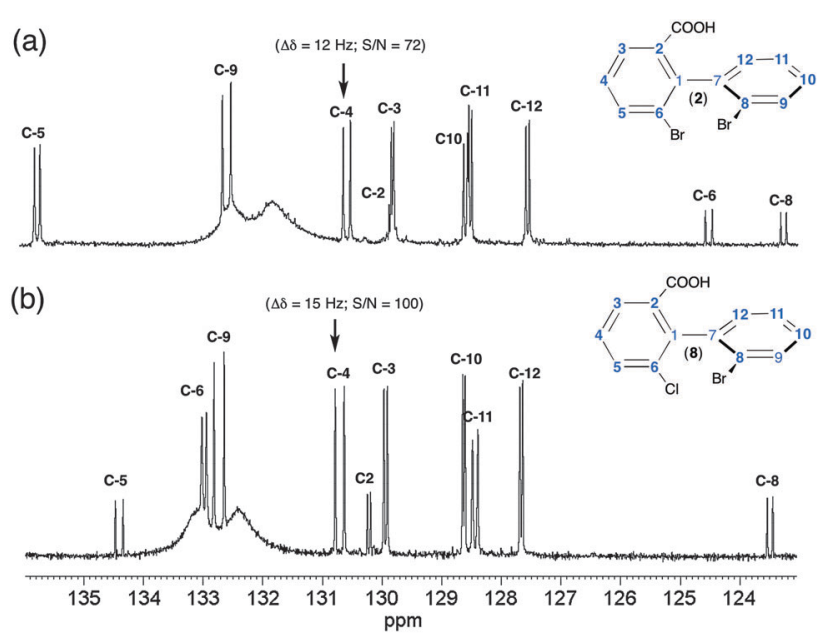

Fig. $3100.4 \mathrm{MHz}{ }^{13} \mathrm{C}-\left\{{ }^{1} \mathrm{H}\right\}$ 1D spectra (BBO probe) of (a) $(R / S)-2$ and (b) $(R / S)-8$ recorded in $\mathrm{PBLG} / \mathrm{CHCl}_{3}$. Only the region ranging from 123 to $136 \mathrm{ppm}$ is displayed (carbon atoms $\mathrm{C}-1 / \mathrm{C}-7$ and from carboxyl group not shown). Note the doubling of numerous ${ }^{13} \mathrm{C}$ signals (compared to isotropic spectra) associated to the spectral discrimination of $R / S$ isomers. The very broad resonances observed around 132-134 ppm originate from ortho/ meta aromatic ${ }^{13} \mathrm{C}$ signals of the benzyl group of the PBLG side chain.

Furthermore, the ${ }^{13} \mathrm{C}$ CSA is weakly sensitive to small variations of $T$ or sample concentration.

Due to the diversity of contributing factors/effects to the CDMs (molecular shape, electronic properties and/or conformational dynamics), the attempt to establish qualitative correlations between the enantiodiscrimination efficiency and molecular properties is far from being trivial. Nevertheless, it is important to investigate them in order to rank their role and evaluate their respective predominance contributing to the CDMs. This is a prerequisite step toward a global insight of the phenomenon, and subsequently the possibility to predict spectral results for any given analyte.

Considering the rather high degree of structural homology (ortho-three-substituted biaryl) of analytes in series I and II, we have first attempted to simply correlate (and explain) the ${ }^{13} \mathrm{C}$ NDS and the range of spectral separations $\left(\Delta \Delta \sigma\left({ }^{13} \mathrm{C}\right)\right.$ ) (weak (1-3 Hz), medium $(4-8 \mathrm{~Hz})$ or large $(>9 \mathrm{~Hz})$ ) to the magnitude of the global dipolar moment of the molecule, $\mu_{\text {mol }}$, calculated by molecular modeling. For this purpose, the dipole moments (in $\mathrm{CHCl}_{3}$ ) for all biaryls in their lowest-energy conformation have been calculated using solvent-dependent density functional theory (SCRF-DFT) Mulliken charge distribution analysis (see Experimental section for details). The scalar value is listed in Table 1, while the value on the three-axis components $(x, y, z)$ and their vectorial representation are reported in Table S4 (ESI $\dagger$ ). A first inspection of the molecular modelling results shows that: (i) the variation of $\mu_{\mathrm{mol}}$ does not exceed $7 \%$ when $\mathrm{Br}$ is replaced by the chlorine atom; and (ii) the nature of substituent Y modifies significantly $\mu_{\text {mol }}$, from 2.1 (1) to $4.2 \mathrm{D}$ (4).

The comparison of NMR results between series I and II shows rather similar results $\left(\operatorname{NDS}\left({ }^{13} \mathrm{C}\right)\right.$ and $\left.\Delta \Delta \sigma\left({ }^{13} \mathrm{C}\right)\right)$, thus indicating that the replacement of $\mathrm{Br}$ by $\mathrm{Cl}$ in position 6 (ring $\mathrm{A}$ ) does not change strongly the global molecular properties 
(dipole moment and shape) of the solute towards the efficiency of CDMs. In contrast, in each series, the difference of properties of ligand $\mathrm{Y}$ has a larger impact on both criteria. Except for solutes 1 and 7, which both exhibit the smallest values of $\mu_{\mathrm{mol}}$ and NDS (with small $\Delta \Delta \sigma$ ), the analysis of results for other analytes indicates that there is no simple dependency (i.e. a monotonous variation) between both spectral criteria and the magnitude of global dipole moment. In clear, the larger NDS does not occur for the biggest $\mu_{\mathrm{mol}}$. This absence of direct correlation suggests that the nature of substituent $\mathrm{Y}$ and the associated specific electronic properties (presence of labile hydrogens able to form intermolecular hydrogen bondings (HB) or the presence of electronegative oxygen in carbon-oxygen double bond, for instance) play a crucial role in the efficiency of CDM for this series of biaryls, independently to the global molecular dipole moment. Thus, the best results obtained with acid derivatives $\mathbf{2}$ and 8, and not for the methyl ester analogues (6 and 11), point out that the possibility of forming HB between the substituent $\mathrm{Y}$ and the oxygen of the carboxylate group of the PBLG side chain is of primary importance in the CDM. Schematically, the role of $\mathrm{HB}$ can be understood as follows. Contrarily to ordering mechanisms (mainly due to the coupling between the solute quadrupole moment and the electric field gradient of the solvent), the CDMs involve short-range intermolecular interactions that derive from the repulsive forces correlated with the size and shape (and the shape-anisotropy) of the solute. ${ }^{31}$ Hence, the CDM efficiency is strongly dependent on the average distance between the solute and the PBLG chiral helix. In this context, irrespective of the magnitude of the global dipole moment, HB can be seen as a crucial local electronic interaction susceptible to bring the solute nearest the fibers (at small distances), in turn promoting better enantiodiscriminations, this effect being particularly strong when the labile hydrogen is highly topologically accessible, as in the case of $\mathbf{2}$ and $\mathbf{8}$.

When no $\mathrm{HB}$ are possible, other attractive specific electronic interactions can play important roles in the CDM, in particular to reduce the average solute-PBLG distance. Although probably less efficient than $\mathrm{HB}$, these (secondary) interactions then become key parameters governing the efficiency of discrimination. Clearly the presence of an electronegative oxygen atom with accessible lone pairs (aldehydic or ester groups for instance) appears as an important electronic parameter favoring fibersolute electrostatic interactions (van der Waals type). In contrast (vide infra), it is a priori expected that CDM are much less efficient for biaryls devoid of any groups susceptible to promote any attractive intramolecular interactions (case 5 and 10). This simply explains why better results are obtained for methoxy, carbonyl or ester groups (NDS varying from 8/13 to 10/13), whereas the situation is much less favorable for methyl group (NDS $=6 / 13)$. From the spectral enantiodiscrimination viewpoint, the case of methoxy or aldehydic derivatives $(\mathbf{3}, \mathbf{4}, \mathbf{9}, \mathbf{1 7})$ could be qualified as an "intermediate" situation for which only enantiodiscriminations with moderate spectral differences are expected and occur.

As an illustrative example of the experimental quantification of ee's of enantioenriched chiral biaryl mixtures, Fig. 4 compares

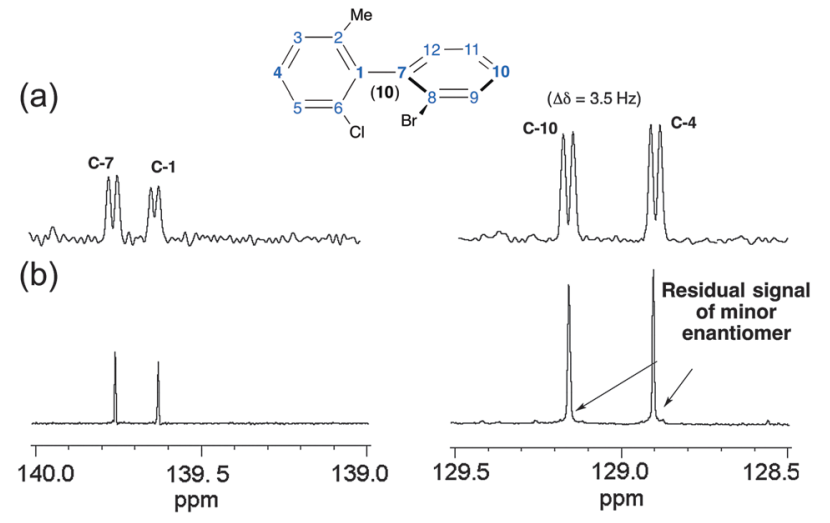

Fig. 4 Comparison of ${ }^{13} \mathrm{C}-\left\{{ }^{1} \mathrm{H}\right\} 1 \mathrm{D}$ signals of carbons $\mathrm{C}-1, \mathrm{C}-4, \mathrm{C}-7$ and $\mathrm{C}-10$ of 10 in (a) racemic and (b) enantiopure series $(R)$ recorded with $4 \mathrm{k}$ and $8 \mathrm{k}$ scans added, respectively. For those four sites, enantiodiscrimination is observed. The ee measured is about $95 \%$.

the signals of four ${ }^{13} \mathrm{C}$ sites of $\mathbf{1 0}$ in racemic (top) and enantioenriched mixtures $(R)$ (bottom). Thus, in the enantioenriched series, a single resonance is observed at quaternary carbons (C-1 and C-7) for which the SNR is smaller (137 and 114) compared to para methine sites (C-4 and C-10) $(\mathrm{SNR}=317$ and 375). In contrast, for the latter case, a very weak signal can be found at the foot of the most intense ${ }^{13} \mathrm{C}$ signal, indicating that the mixture is not enantiopure but only enantioenriched (see Fig. 4b, right panel). Evaluation of peak areas by deconvolution indicates an ee of about 95\% (in good agreement with the chromatographic results), ${ }^{8}$ while the absence of signals for the minor enantiomer at quaternary carbon atoms (C-1 and C-7) could suggest an ee of $100 \%$. This example points out the importance of sites selected for quantitative measurement, in particular when a reliable evaluation of ee is necessary. The analysis of ${ }^{13} \mathrm{C}-\left\{{ }^{1} \mathrm{H}\right\}$ spectra of molecules of series IV is analytically much more challenging for two reasons: (i) the important number of $\mathrm{sp}^{2}$ carbon atoms (up to 24 sites) in the aromatic region ranging from 123 to 145 ppm (12 and 13); and (ii) the weak distribution of chemical shifts of $\mathrm{sp}^{3}$ carbon atoms in the aliphatic region (from 25 to $34 \mathrm{ppm}$ ) of cyclohexyl rings (14 and 15). For all phosphorous analytes, the determination of $\delta\left({ }^{13} \mathrm{C}\right)$ listed here was achieved from the analysis and the intercomparison of ${ }^{13} \mathrm{C}-\left\{{ }^{1} \mathrm{H}\right\}$ and ${ }^{13} \mathrm{C}-\left\{{ }^{1} \mathrm{H},{ }^{31} \mathrm{P}\right\}$ 1D-NMR spectra and ${ }^{13} \mathrm{C}-\left\{{ }^{1} \mathrm{H}\right\}$ and ${ }^{13} \mathrm{C}-\left\{{ }^{1} \mathrm{H},{ }^{31} \mathrm{P}\right\} J$-modulated $1 \mathrm{D}$-NMR spectra. All $\delta\left({ }^{13} \mathrm{C}\right)$ measured (and the associated $\left.|\Delta \Delta \sigma|\right)$ at $9.4 \mathrm{~T}$ are reported in Table $\mathrm{S} 3$ (ESI $\dagger$ ). Globally, the results from the ${ }^{13} \mathrm{C}$ enantiodiscrimination side are rather mediocre and disappointing because only very few carbon sites (with tiny spectral differences) show useful separation both in phenyl and cyclohexyl rings. Actually, two reasons may explain the absence of numerous and large differentiations. The first one is related to the presence of $\mathrm{sp}^{3}$ carbon atoms in cyclohexyl groups (14 and 15), which are less susceptible to discrimination on the basis of ${ }^{13} \mathrm{C}$ chemical shift anisotropy (spherical electronic screening). The second one could originate from the global shape of the molecule. Indeed, the presence of a biphenylphosphine (oxide or not) moiety significantly increases the size 
(a)

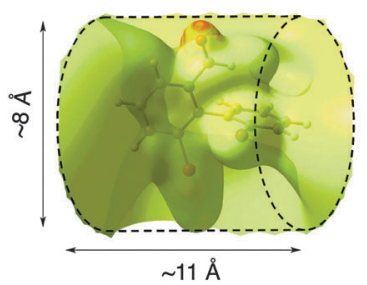

(b)

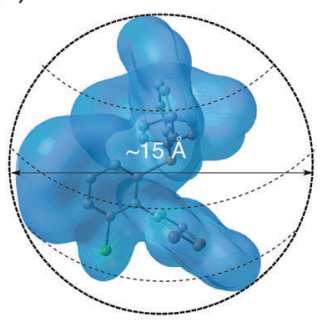

Fig. 5 Two examples of electrostatic potential (ESP) surfaces (by plotting only their positive contribution and restraining the contour level with isovalues of 0.005 a.u. for both cases) associated to (a) $\mathbf{3}$ and (b) 12 .

of the structure (four cycles), and concomitantly leads to a more globular molecular topology (regardless of the conformational dynamics). In a simple (static) schematic view, increasing of the number of (aromatic or aliphatic) cycles reduces the geometrical shape anisotropy (compared to molecules of series I and II), and in turn the efficiency of shape recognition mechanisms, which are also another key parameter in the CDM. ${ }^{17 b}$ To illustrate this idea, Fig. 5 shows the electronic topologies of $\mathbf{3}$ and $\mathbf{1 2}$ displayed in terms of the DFT-computed electrostatic potential contour plots associated to the optimized electronic structures. As seen, the surfaces for these two examples significantly differ from each other. Thus, solute 3 shows a rather cylindrical topology (with a diameter $(D)$ of about $8 \AA$ and a length $(L)$ of about $11 \AA$, leading to a $D / L$ ratio of 0.72 ) whereas $\mathbf{1 2}$ has a roughly spherical topology (with $D \approx 15 \AA$ ). Actually, the former is representative of the topology (rod-like type) adopted by biaryls of series I and II (including also 17 of series IV), whose $D / L$ ratios differ accordingly with the nature of the $\mathrm{X}$ and $\mathrm{Z}$ substituents. In contrast, the latter (a rather spherical shape) is representative of series III (including also analyte $\mathbf{1 6}$ of series IV), whose $D$ varies between 15 and $18 \AA$ (see Table S4, ESI $\dagger$ ). Reasonably, the shape recognition mechanisms where the topological anisotropy plays a substantial role are expected to be less efficient in the second case.

\section{${ }^{1} \mathrm{H}$-coupled ${ }^{13} \mathrm{C}$ 1D-NMR}

At a first glance, and compared to ${ }^{13} \mathrm{C}-\left\{{ }^{1} \mathrm{H}\right\}$ NMR in CLC, ${ }^{13} \mathrm{C}$ NMR might be seen to be of limited practical interest for two reasons: (i) the complexity of spectral pattern due to the presence of both short range $\left({ }^{1} D_{\mathrm{CH}}\right)$ and long range $\left({ }^{n} D_{\mathrm{CH}}, n=2,3\right)$ RDCs; and (ii) the distribution of ${ }^{13} \mathrm{C}$ signals on numerous lines, thus reducing the SNR, and hence the accuracy of the ee. However, this approach must be kept in the panel of tools because it can also provide a solution to reveal chiral discriminations. In particular, it can be a useful alternative to ${ }^{13} \mathrm{C}-\left\{{ }^{1} \mathrm{H}\right\}$ NMR when molecules possess few or no $\mathrm{sp}, \mathrm{sp}^{2}$ carbon atoms. Besides, using simple heteronuclear 2D-NMR experiments (see below), it becomes possible to simplify the spectral analysis of fine ${ }^{13} \mathrm{C}-{ }^{1} \mathrm{H}$ structures, while the measurement of peak volumes on 2D maps allows the determination of the ee when the signal of each enantiomer has been identified.

Another potential source of useful information can be found from the analysis of ${ }^{13} \mathrm{C}$ signals of substituent $\mathrm{Y}$ (see Fig. 1),

(a)

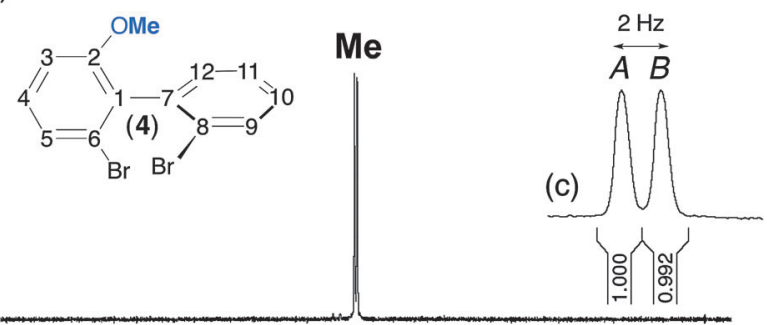

(b)

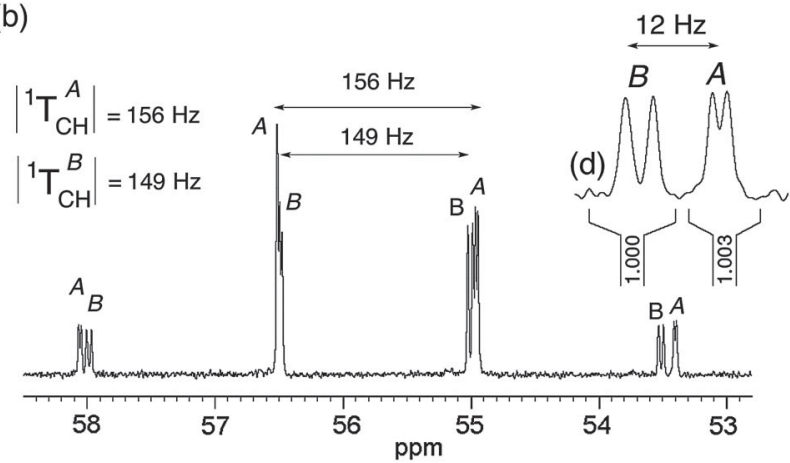

Fig. 6 Comparison of ${ }^{13} \mathrm{C}$ signals of the methyl group of $(R / S)-4$ dissolved in $\mathrm{PBLG} / \mathrm{CHCl}_{3}$ recorded with (a) and without (b) ${ }^{1} \mathrm{H}$ decoupling (4k scans added). Inset (c): zoom on resonances. Inset (d): zoom on the deshielded components of two quadruplets. Integrations of lines (or groups of lines) associated to each enantiomer and showing that ee $=0 \%$.

in particular when small (isolated) groups such as methyl or methoxy are present. Indeed such moieties can lead to very simple spectral patterns to analyze since they are primarily governed by direct ${ }^{1} D_{\mathrm{CH}}$, which in turn gives rise to quadruplet structures (of relative intensities $1: 3: 3: 1$ ). Such a relevant spectral situation exists for $\mathbf{4}$, for which two slightly shifted quadruplets $(\Delta \Delta \sigma=2 \mathrm{~Hz})$ with two different total couplings $\left(\left|T_{\mathrm{CH}}^{A}\right|=156 \mathrm{~Hz}\right.$ and $\left.\left|{ }^{1} T_{\mathrm{CH}}^{B}\right|=149 \mathrm{~Hz}\right)$ appear on the ${ }^{13} \mathrm{C}$ spectrum. Assuming that $T$ is positive, we obtain ${ }^{1} D_{\mathrm{CH}}^{A}=-3.5 \mathrm{~Hz}$ and ${ }^{1} D_{\mathrm{CH}}^{B}=$ $-7 \mathrm{~Hz}\left({ }^{1} J_{\mathrm{CH}}=+163 \mathrm{~Hz}\right)$. The presence of further doubling is due to one remote dipolar coupling, whose magnitudes differ for each enantiomer. The differences of fine structures for the four components of the quadruplet originate from the various combinations of lines, which also depend on the difference of ${ }^{13} \mathrm{C} \mathrm{CSA}(2 \mathrm{~Hz})$ and the short- and long-range ${ }^{13} \mathrm{C}-{ }^{1} \mathrm{H}$ RDCs as well. The assignment of ${ }^{13} \mathrm{C}$ resonances shown in Fig. $6 \mathrm{~b}$ has also been supported by the analysis of the associated ${ }^{13} \mathrm{C}-{ }^{1} \mathrm{H}$ heteronuclear $T$-resolved 2D map. In this example, the shielded component of the quadruplet provides the best site for a quantitative measurement of ee (see Fig. 6).

\section{Heteronuclear correlation 2D-NMR approaches}

Except for particular cases (as discussed previously), the analysis of proton-coupled ${ }^{13} \mathrm{C}$ 1D-NMR in CLC cannot be simply performed, and hence heteronuclear correlation 2D-NMR experiments are needed to tentatively extract the useful spectral information for quantitative purposes. During the last decade, a large panel of heteronuclear 2D experiments (involving HSQC scheme) has been explored to extract one bond ${ }^{1} \mathrm{H}^{-13} \mathrm{C}$ dipolar couplings. ${ }^{32}$ 
However, the control of ${ }^{1} \mathrm{H}-{ }^{13} \mathrm{C}$ polarization transfer efficiency (for quantitative measurement of ee dissolved in CLC) can be subtle and time-consuming for routine NMR users. Considering the framework of this study, we only focused our purpose on 2D experiments based on the well-known heteronuclear "J-resolved" schemes. ${ }^{33}$ As in CLC, the $T$ couplings replace the $J$ couplings, so the experiments were renamed " $T$-resolved" $2 \mathrm{D}$ experiments, but the pulse scheme remains identical. As expected, the ${ }^{13} \mathrm{C}$ chemical shifts are refocused during $t_{1}$ while the $T\left({ }^{13} \mathrm{C}-{ }^{1} \mathrm{H}\right)$ couplings are removed during acquisition by ${ }^{1} \mathrm{H}$ decoupling. As the ${ }^{13} \mathrm{C}-{ }^{1} \mathrm{H}$ T couplings evolve only during half of the $t_{1}$ evolution period (gated-decoupled method), the $T$ values are scaled down by a factor of 2 . Modified sequences of the basic "T-resolved" experiment might be proposed. For instance, with the view of simplifying the coupling structures in $F_{1}$, a BIRD cluster can be incorporated to differentiate long-range from direct couplings. ${ }^{34}$ Additionally, the sensitivity could be improved by incorporating INEPT or DEPT pulse trains as an initial transfer step. ${ }^{35}$ Nevertheless, one can be faced with either distorted lines or important differences with the transfer efficiency, leading to less accurate ee measurements.

Fig. 7 displays the region of the $T$-resolved 2D spectrum where ${ }^{1} \mathrm{H}-{ }^{13} \mathrm{C}$ coupling patterns and ${ }^{13} \mathrm{C}$ chemical shifts associated to C-10 and C-11 atoms of 2 appear in $F_{1}$ and $F_{2}$ dimensions, respectively. The analysis of the map allows the relevant information for each carbon site and each enantiomer (noted $A$ and $B$ ) to be separated. For each of them, the spectral pattern is dominated by the direct ${ }^{1} T_{\mathrm{CH}}$ coupling, which is different for each enantiomer $\left(\left|{ }^{1} T_{\mathrm{CH}}^{\mathrm{A} / B}(\mathrm{C}-10)\right|=459 / 528 \mathrm{~Hz}\right.$ and $\left.\left|{ }^{1} T_{\mathrm{CH}}^{\mathrm{A} / B}(\mathrm{C}-11)\right|=106 / 82 \mathrm{~Hz}\right)$, as seen on the map. Interestingly, we can measure a large difference of ${ }^{1} T_{\mathrm{CH}}\left(\Delta^{1} T_{\mathrm{CH}}\right)$ of about $70 \mathrm{~Hz}$ at site C-10. As ${ }^{1} T_{\mathrm{CH}}^{A / B}=$ ${ }^{1} J_{\mathrm{CH}}^{A / B}+2^{1} D_{\mathrm{CH}}^{A / B}$, the magnitude of ${ }^{1} T_{\mathrm{CH}}^{\mathrm{A} / B}(\mathrm{C}-11)$ suggests that the sign of ${ }^{1} D_{\mathrm{CH}}^{A / B}$ is negative (compared to ${ }^{1} J_{\mathrm{CH}}^{A / B}$, which is always positive and ranging from $150-160 \mathrm{~Hz}$ for aromatic carbons). ${ }^{36}$ Note that a similar spectral situation was also observed for the $\mathrm{C}-11$ site of 3 (see Fig. S5, ESI $\dagger$ ). Indeed, here again the ${ }^{1} T_{\mathrm{CH}}^{\mathrm{A} / B}(\mathrm{C}-11)$ value $(66 / 74 \mathrm{~Hz})$ is smaller than ${ }^{1} J_{\mathrm{CH}}(\mathrm{C}-11)$, thus indicating that ${ }^{1} D_{\mathrm{CH}}^{A / B}<0$. The further splittings (at C-10) and triplets (at C-11) observed on the map originate from the ${ }^{n} T_{\mathrm{CH}}$ long-range couplings. For both sites, the separation of coupling patterns in $F_{1}$ is facilitated by the ${ }^{13} \mathrm{C}$ chemical shifts difference between enantiomers. The presence of two triplets (for each enantiomer) is quite unusual but can be explained if C-11 is coupled identically with two inequivalent aromatic protons in the vicinity of $\mathrm{C}-11$ ( 62 and $64 \mathrm{~Hz}$ for $A$ and $B$, respectively).

The large magnitude of ${ }^{1} D_{\mathrm{CH}}^{A / B}(148$ and $170 \mathrm{~Hz}$ ) for C-10 whereas ${ }^{1} J_{\mathrm{CH}}=+164 \mathrm{~Hz}$ indicates that the $\mathrm{C}_{10}-\mathrm{H}$ direction is strongly ordered. Actually, the analysis of other carbon sites of 2 (and 8, also) confirms a rather strong degree of molecular alignment compared to other solutes, leading to large (and unusual) ${ }^{1} D_{\mathrm{CH}}$ values. This result suggests the presence of HB in the orientation mechanisms of 2 (and 8) leading to a decrease of the average distance between the analyte and the fiber, and hence an increase of the average degree of alignment of the solute. Locally, it is expected that the ordering of each $\mathrm{C}-\mathrm{H}$ vector $\left(S_{\mathrm{CH}}\right)$, and in turn the associated RDC value, increase.

In a framework of a crude two-site interaction model, we can simply write that the $S_{\mathrm{ij}}$ order parameter is a weighted sum of

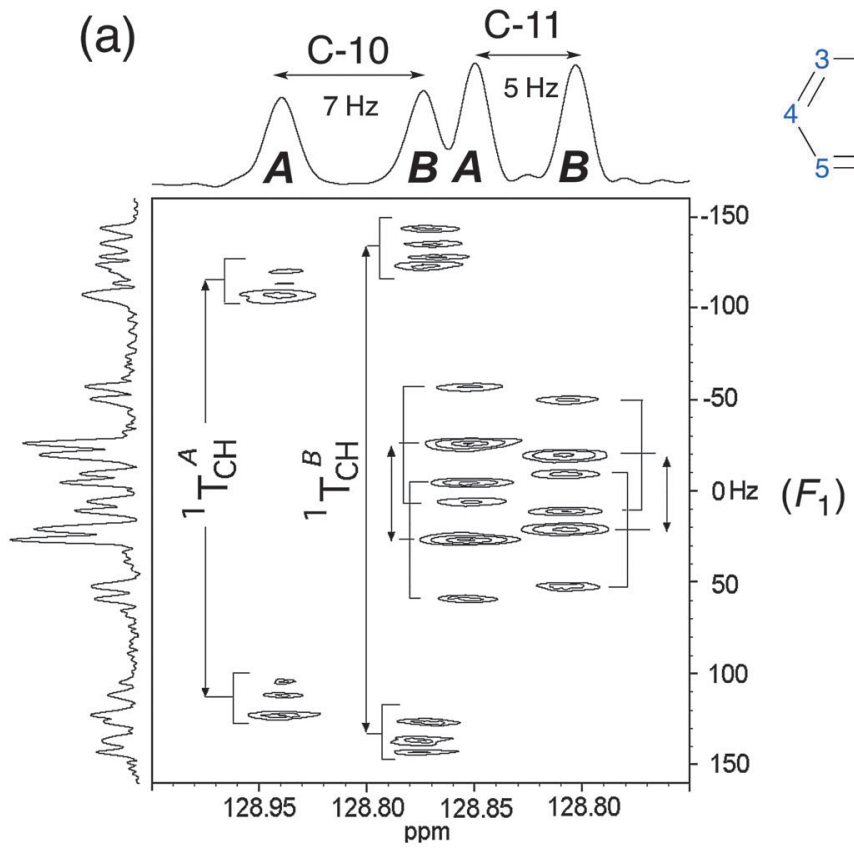

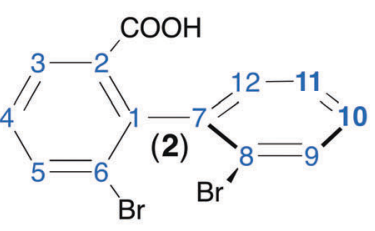

(b)
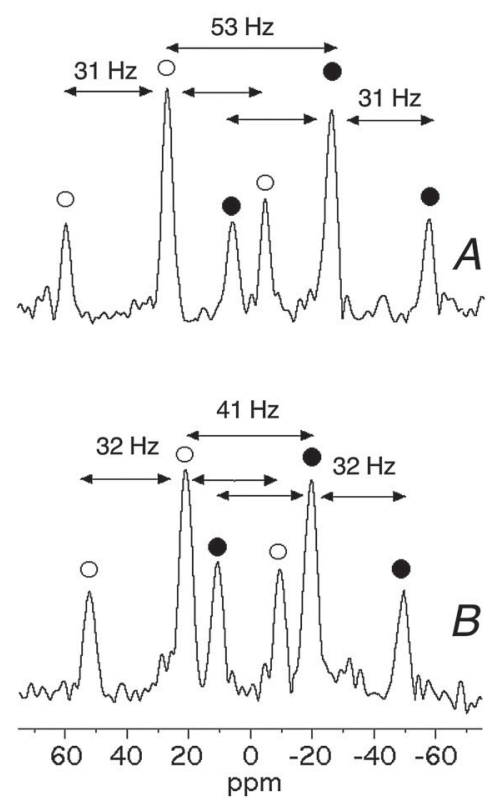

$\left(F_{2}\right)$

Fig. 7 (a) Expanded region (centered on $\mathrm{C}-10$ and $\mathrm{C}-11$ sites) of ${ }^{13} \mathrm{C}-{ }^{1} \mathrm{H} T$-resolved $2 \mathrm{D}$ spectra of $(R / S)-2$ in $\mathrm{PBLG} / \mathrm{CHCl} 3$ (see Fig. $2 \mathrm{a}$ ). (b) Two vertical slices extracted from the $T$-resolved map project two dedoubled triplets, one per enantiomer. Each of the $(1: 2: 1)$ intensity patterns in (b) is highlighted with filled and unfilled circles for visualization purposes. The $T$ values (in $\mathrm{Hz}$ ) given in (b) are half of the true values. 
two situations corresponding to the case where the solute is either close to the polypeptide fibers (bonded) or at remote location (free):

$$
S_{\mathrm{ij}}^{\mathrm{Obs}}=P^{\text {bonded }}\left(S_{\mathrm{ij}}^{\mathrm{bonded}}\right)+P^{\text {free }}\left(S_{\mathrm{ij}}^{\mathrm{free}}\right)
$$

where $P^{\text {bonded }}$ and $P^{\text {free }}$ are the normalized population ratios of solute $\left(P^{\text {bonded }}+P^{\text {free }}=1\right)$. From the NMR viewpoint, we can subsequently write that:

$$
\mathrm{Obs}_{\mathrm{i}}=P^{\text {bonded }}\left(\mathrm{Obs}_{\mathrm{i}}^{\text {bonded }}\right)+P^{\text {free }}\left(\mathrm{Obs}_{\mathrm{i}}^{\text {free }}\right)
$$

where $\mathrm{Obs}_{\mathrm{i}}$ stands for NMR observable at site $\mathrm{i}\left(\Delta \sigma_{\mathrm{i}}, D_{\mathrm{ij}}\right.$ or $\left.\Delta \nu_{\mathrm{Qi}}\right)$ and is associated to NMR nuclei detected. In this very simple approach, the solute is strongly oriented in close vicinity to the helix, and not oriented (or very weakly oriented) when the solute is distant from the helix; the respective population and associated splittings directly depend on the strength of interactions between the solute and PBLG.

\section{${ }^{31} \mathbf{P}-{ }^{31} \mathbf{P}$ correlation $2 D-N M R$ experiments}

As explained previously, the comparison of the ${ }^{31} \mathrm{P}-\left\{{ }^{1} \mathrm{H}\right\}$ 1D-NMR spectrum of diphosphino biphenyl 16 recorded in racemic and enantioenriched series leads to a rapid assignment of the absolute configuration of lines in the spectrum of the racemic mixture (vide supra). However, this is only possible when an enantioenriched mixture or an enantiopure compound is available and the absolute configuration of the major isomer is known. When the racemic mixture is only available, the assignment of various ${ }^{31} \mathrm{P}$ peaks of $( \pm)-\mathbf{1 6}$ is obviously not straightforward. Indeed the positions of ${ }^{31} \mathrm{P}$ resonances can be explained by a difference of ${ }^{31} \mathrm{P}$ CSA or ${ }^{31} \mathrm{P}$ RDC, or both (see Fig. 2). To clear up this ambiguity, various homonuclear 2D-NMR approaches were tested to correlate the ${ }^{31} \mathrm{P}$ resonances to each enantiomer of the mixture: the ${ }^{31} \mathrm{P}-{ }^{31} \mathrm{P}$ COSY, T-resolved and INADEQUATE $2 \mathrm{D}^{11,37}$ experiments, no knowledge of ${ }^{31} \mathrm{P}-{ }^{31} \mathrm{P}$ RDC being requested for the first two. Experimental maps and comments on the experimental results are proposed in ESI. $\dagger$

\section{The NAD 2D-NMR approach}

The main feature of NAD NMR is mainly its low sensitivity due to the very weak natural abundance of deuterium nuclei $(1.5 \times$ $10^{-2} \%$ ), namely 100 fold less than ${ }^{13} \mathrm{C}$ nuclei. Besides using CLC, the intensity of NAD signals for a given ${ }^{2} \mathrm{H}$ site is reduced by a factor four when spectral discrimination occurs. Indeed, the single ${ }^{2} \mathrm{H}$ peak observed in achiral liquids (see Fig. S2, ESI $\dagger$ ) is now split into four resonances (two quadrupolar doublets), hence reducing the SNR, and subsequently the error in the ee value, in particular when the ee's are large. Technically, this situation can be partly overcome using high-field NMR spectrometers, equipped with cryogenic probes when possible. However, the efficiency/interest of this tool will depend primarily on the available amount of analyte, concomitantly to its MW. In this study, the MW of the solutes ranges from 282 to $557 \mathrm{~g} \mathrm{~mol}^{-1}$, while the available amounts vary from 20 to $100 \mathrm{mg}$ (half of these masses for each enantiomer). Under these conditions, NAD 2D-NMR experiments in CLC have been only recorded for solutes 2 to $4,6,9,11$ and 17 , for which a sufficient mass of solute was available (see Table 1); this corresponds to a mole number varying from 7.65 to $18.2 \times 10^{-5}$ mol, namely a mole number of monodeuterated isotopomers $\left[{ }^{2} \mathrm{H}\right]$ varying from 11.8 to $28.2 \times 10^{-9} \mathrm{~mol}$. The number of discriminated ${ }^{2} \mathrm{H}$ sites for each analyte is reported in Table 1 (see also Table S2, ESI $\dagger$ ).

The analytical interest of NAD 2D-NMR is the possibility to separate the useful information on two spectral dimensions (see Fig. S12 to S14, ESI $\dagger$ ). Thus on the tilted NAD $Q-C O S Y ~ F z$ map of 17 (Fig. S12, ESI $\dagger$ ), we can easily assess that seven ${ }^{2} \mathrm{H}$ sites (over nine) show spectral discrimination (77\%). The presence of three DQ (instead of 4 ) associated to sites 10 and 12 resonating at the same $\delta\left({ }^{2} \mathrm{H}\right)$ can lead to two possible interpretations from the discrimination viewpoint: (i) two quadrupolar doublets (QD) for site 12 and one for site 10; and (ii) two QD for sites 10 and 12, considering that both internal doublets for each site possess the same splitting. Actually, the second analysis is less probable for three reasons: (i) the differences of RQCs $\left(\Delta \Delta \nu_{\mathrm{Q}}=\left|\Delta \nu_{\mathrm{Q}}^{R}-\Delta \nu_{\mathrm{Q}}^{S}\right|\right)$ for each aromatic site are quite similar (ranging from 210 to $355 \mathrm{~Hz}$ for the outer one and from 167 to 278 for the inner one); (ii) in the structure, the $\mathrm{C}-{ }^{2} \mathrm{H}_{10}$ and $\mathrm{C}-{ }^{2} \mathrm{H}_{4}$ bonds are collinear (para position), and hence the order parameters (and their associated $\Delta \nu_{\mathrm{Q}}$ 's) are expected to be similar for both $\mathrm{C}-{ }^{2} \mathrm{H}$ vectors (124 and $140 \mathrm{~Hz}$ respectively); and (iii) the absence of discrimination at both sites. The analysis of the aliphatic region indicates that both methyl and methoxy groups are discriminated (until the baseline) with RQCs differences of 24.0 and $23.4 \mathrm{~Hz}$, respectively, namely $12 \mathrm{~Hz}$ between $R$ and $S$ components of doublets. Due to the free rotation of methyl deuterons around the $\mathrm{C}-\mathrm{C}$ bond ( 1 rotor) or $\mathrm{C}-\mathrm{O}-\mathrm{C}$ bonds ( 2 rotors), the RQC values are averaged down compared to the RQCs of aromatic ${ }^{2} \mathrm{H}$ sites (from 3-10 fold less). Interestingly, the contribution of three deuterons to the NAD signals increases the SNR (162 and 146) compared to the aromatic sites, thus providing the two best sites to accurately determine the enantiomeric excesses.

Except for analytes $\mathbf{2}$ and $\mathbf{8}$ (see below), the distribution in magnitude of the RQCs of the aromatic ${ }^{2} \mathrm{H}$ QDs observed on the NAD 2D map is globally quite similar for the various analytes (see Fig. S12 and S13, ESI, $\dagger$ for instance). In contrast, the RQCs measured for the ${ }^{2} \mathrm{H}$ sites of the flexible $\mathrm{Y}$ substituent show large variations in magnitude. In order to illustrate this, Fig. 8 compares the NAD 1D signals of the aldehyde groups of 3 and 9 and methyl groups of 4/17 and 11/17 (see Fig. S15, ESI $\dagger$ for the full $2 \mathrm{D}$ map of 6 and 11). For each case, the spectral enantiodiscrimination on Y occurs with differences of RQCs, $\left|\Delta \Delta \nu_{\mathrm{Q}}\right|$, varying from $5 \mathrm{~Hz}(\mathbf{1 1})$ to $35 \mathrm{~Hz}(4)$, while the average of the corresponding RQCs varies from $129 \mathrm{~Hz}$ to $28.5 \mathrm{~Hz}$. The large variation of SNR between the methine and methyl group originates from the number of ${ }^{2} \mathrm{H}$ nuclei contributing to signals (1 to 3 ) but also the mass ( $60 \mathrm{mg}$ to $100 \mathrm{mg}$ ) and the MW (277 to 370 ) of each sample, and possibly some variations of isotopic ratio from one site to another (but not between enantiomers).

Various comments can be made on this series of results, in particular on the variation of RQCs and the magnitude of enantiodiscriminations for the different ${ }^{2} \mathrm{H}$ sites. Indeed, the comparison of results indicates that there is not a simple correlation between the magnitude of RQCs, $\left|\Delta \nu_{\mathrm{Q}}\right|$, the RQC's 

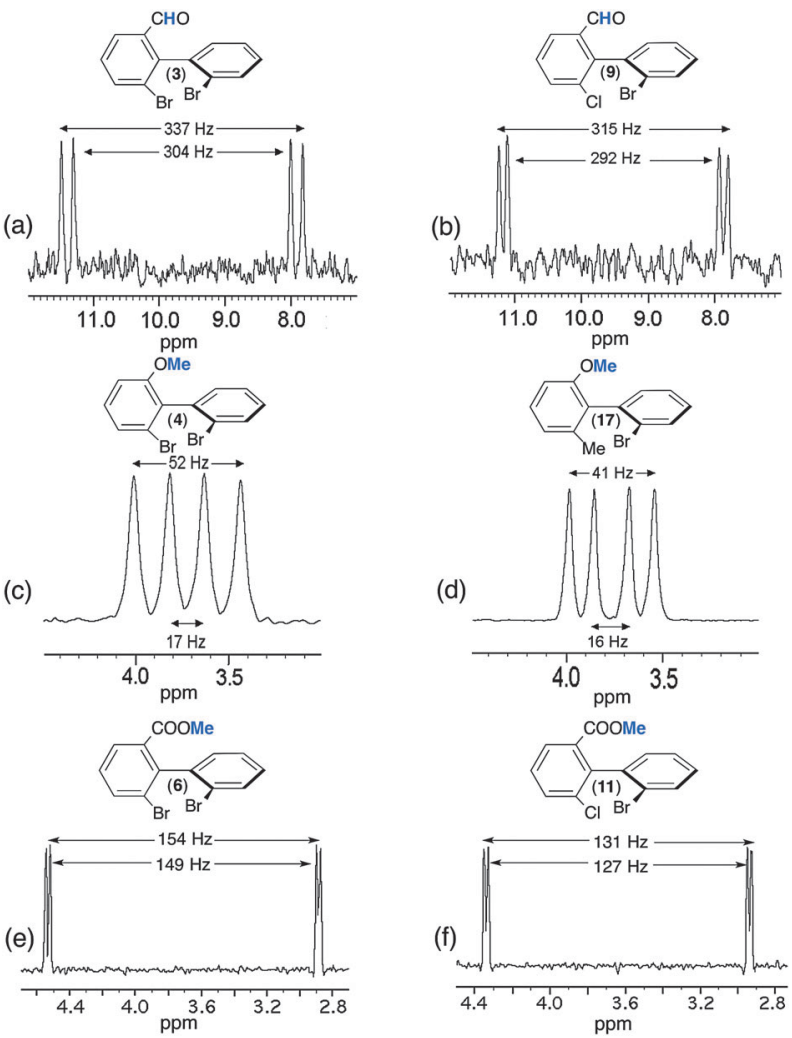

Fig. 8 92.1 MHz proton-decoupled NAD 1D-NMR signals of ( $a$ and $b$ ) the methine of the aldehyde group of $(R / S)-3$ and $(R / S)-9$, of ( $c$ and $d$ ) the methyl of the methoxy group of $(R / S)-4$ and $(R / S)-17$ and of (e and f) the methyl of the ester group of $(R / S)-\mathbf{6}$ and $(R / S)-\mathbf{1 1}$, all of them dissolved in $\mathrm{PBLG} / \mathrm{CHCl}_{3}$ at $295 \mathrm{~K}$. All patterns are extracted from their tilted NAD $Q$-COSY Fz map. Except for e and $f$ (see Fig. S10, ESI $\dagger$ ), an exponential filtering $(\mathrm{LB}=2 \mathrm{~Hz})$ is applied on both dimensions.

difference between enantiomers, $\left|\Delta \Delta \nu_{\mathrm{Q}}\right|$, and the number of rotors in the ligand $\mathrm{Y}$ (one for 3 and 9), two for 4 and 17, and three for 6 and 11. Actually, various (sometimes contradictory) effects, such as the difference of electronic properties of each ligand (aldehyde, ether and ester group) and the position (number of rotors) of the ${ }^{2} \mathrm{H}$ site in the ligand can be evoked to explain the results. Thus, the large magnitude of RQCs for 3 and 9 associated to a strong degree of alignment of the $\mathrm{C}-\mathrm{H}$ direction could suggest a strong site-specific interaction (chargetransfer interactions) between the carbonyl polar group and the PBLG fiber, despite the free rotation around the $\mathrm{C}-\mathrm{C}$ bond. The large difference of $\mid \Delta \nu_{\mathrm{Q}}$ 's $\mid$ (from 34 to 150) and $\mid \Delta \Delta \nu_{\mathrm{Q}}$ 's $\mid$ (from 35 to 5) observed for the methyl groups in 4 (17) and 6 (11) is much more subtle to explain/understand. They both involve significant differences of averaged orientation of the C-D directions, the number of rotors ( 2 and 3 ) between the ring and the ${ }^{2} \mathrm{H}$ site, and the electronic properties of the ligand. On the basis of the rotor number, it could be expected that the $\left|\Delta \nu_{\mathrm{Q}}{ }^{\prime} \mathrm{s}\right|$ for 6 and $\mathbf{1 1}$ would be larger than $\mathbf{4}$ and 17. This trend is not experimentally observed whereas larger $\mid \Delta \Delta \nu_{\mathrm{Q}}$ 's $\mid$ are measured for those latter compared to $\mathbf{6}$ and 11. This illustrates the difference of electronic interaction between ether or carboxylate groups and the PBLG side chain (which can promote a more or less stronger alignment of the $\mathrm{Y}$ ligand), but also the ability of the ${ }^{2} \mathrm{H}$ site to sense the chirality of the biaryl skeleton versus its distance and the number of rotors in the flexible part. Results obtained for the methyl group (6 and 11) suggest that a physical interaction between PBLG and the carboxylate group might generate a higher degree of alignment for the COOMe moiety, and hence for the terminal methyl group, but in this case with a weaker enantiodiscrimination efficiency.

Finally, it must be noticed that the NAD 2D-NMR spectra of the carboxylic acids ( $\mathbf{2}$ and $\mathbf{8}$ ) were not analytically exploitable whereas ${ }^{13} \mathrm{C}-\left\{{ }^{1} \mathrm{H}\right\}$ NMR had provided well-resolved spectra with excellent results in terms of spectral quality and enantiodiscriminations (see Table 1, Table S3, ESI $\dagger$ ). Indeed, 2D maps of 2 and 8 are made of weakly resolved NAD QDs of low intensity, not distinctly emerging from noise (even with strong exponential apodisation), and showing splittings ranging from 1500 to $2000 \mathrm{~Hz}$ (see Fig. S14a/b, ESI $\dagger$ ). These magnitudes of RQCs are unusually large for small solutes oriented in weakly aligning media as those prepared with the PBLG polymer, whereas the symmetrical shape, the linewidth $(3 \mathrm{~Hz})$ and the splitting (around $500 \mathrm{~Hz}$ ) of chloroform both indicate a homogeneous and uniform mesophase that complies with standards when $\mathrm{w} / \mathrm{w}$ $(\mathrm{PBLG})=14 \%$. No significant enhancement was obtained by several rehomogenizations of the sample (new cycles of centrifugations) or by a sample temperature variation.

Although a priori unexpected, the low quality of NAD NMR spectra for $\mathbf{6}$ and $\mathbf{8}$ (due to unusually large RQCs) can be explained by the presence of $\mathrm{HB}$, and again understood in the frame of the simple model proposed above. Derived from eqn (2), we can write that:

$$
\Delta \nu_{\mathrm{Q}}^{\text {obs }}\left({ }^{2} \mathrm{H}\right)=P^{\text {bonded }}\left(\Delta \nu_{\mathrm{Q}}^{\text {bonded }}\left({ }^{2} \mathrm{H}\right)\right)+P^{\text {free }}\left(\Delta \nu_{\mathrm{Q}}^{\text {free }}\left({ }^{2} \mathrm{H}\right)\right)
$$

Thus, the existence of strong hydrogen bonds may lead to an "aggregation effect" of the solute towards PBLG fibers, considerably increasing the solute alignment (and the associated $\Delta \nu_{\mathrm{Q}}$ at each deuterium site), and finally amplifying excessively the RQCs. In the case of NAD NMR, this aggregative effect can appear as spectrally unfavorable (as seen for $\mathbf{6}$ and $\mathbf{8}$ ), because the larger the ${ }^{2} \mathrm{H}$ splittings are, the larger the linewidths for each component of DQ are (effect due to the "disorder" of orientational order), and hence the smaller the SNR are. In the case of 2 , we can note that the magnitude range of RQCs of DQs observed on the NAD map is rather coherent with the range of RDCs measured on the ${ }^{13} \mathrm{C}-{ }^{1} \mathrm{H}$ NMR spectra (see the ${ }^{13} \mathrm{C}-{ }^{1} \mathrm{H} T$-resolved 2D map in Fig. 7) according to the fact that the ratio "RQC/RDC" is equal to 12-14 when $\mathrm{sp}^{2}$ hybridized carbon atoms are involved (this ratio is equal to $11-12$ for $\mathrm{sp}^{3}$ ones). This relationship derives from the fact that ${ }^{13} \mathrm{C}^{1}{ }^{1} \mathrm{H}$ and ${ }^{13} \mathrm{C}^{2} \mathrm{H}$ directions (in the associated isotopomers) are similarly oriented in the mesophase relative to the magnetic field axis, $\mathbf{B}_{0} \cdot{ }^{38}$ Finally, the presence of $\mathrm{HB}$ between 2 and 8 and PBLG is simply evidenced when comparing their NAD spectra with those of ester analogues, 6 and 11, which cannot form HB. While the sample composition is similar to those of the acid derivatives, we obtain exploitable NAD 2D spectra of $\mathbf{1 1}$ where the ranges of RQCs are standard (see Fig. S14, ESI $\dagger$ ). The analysis of both esters indicates that 
$85 \%(6 / 7)$ of the aromatic ${ }^{2} \mathrm{H}$ sites are discriminated $\left(\left|\Delta \Delta \nu_{\mathrm{Q}}\right|=\right.$ 20 to $153 \mathrm{~Hz}$ ) while a small spectral enantiodifference (about $3 \mathrm{~Hz}$ ) is observed on the terminal methyl group.

All these results and arguments point out openly the important role of $\mathrm{HB}$ in the ordering mechanisms of the solute (in particular the degree of molecular orientation) and the related analytical consequences according to the NMR properties of the observed nucleus. Thus, the presence of $\mathrm{HB}$ involving $\mathrm{COOH}$ groups was a major advantage in terms of ${ }^{13} \mathrm{C}$ enantiodiscrimination (on the basis of ${ }^{13} \mathrm{C}$ CSAs) since $85 \%$ of ${ }^{13} \mathrm{C}$ sites showed discriminations, but can lead to undesirable effects visible on the NAD spectra (on basis of ${ }^{2} \mathrm{H}$ RQCs). This beneficial difference results from a more complex and "dilute" dependence of the ${ }^{13} \mathrm{C}$ CSA through the electronic screen tensor (for each ${ }^{13} \mathrm{C}$ site) toward the molecular ordering of a solute compared to $\Delta \nu_{\mathrm{Q}}$. This rather contradictory situation associated to ${ }^{13} \mathrm{C}$ and ${ }^{2} \mathrm{H}$ NMR illustrates nicely some versatile aspects of anisotropic NMR as well as the subtle balance between the orientation and the chiral discrimination.

\section{Importance and role of factors involved in the CDM}

In the frame of the understanding and the phenomenological description of CDMs in polypeptide CLC (and in particular in PBLG), the analysis of the various factors (and their respective role) governing or involving the efficiency of CDM is a necessary step before proposing models describing the phenomenon or a starting point for any computational modeling of the system. A priori, it is difficult to dissociate the topological properties (shape anisotropy) and the electronic profile of a solute due to their strong inherent intrication. However, for a qualitative description of contributive factors, we may propose this artificial separation.

From the analysis of ${ }^{13} \mathrm{C}-\left\{{ }^{1} \mathrm{H}\right\}$ NMR results of this study (data from seventeen solutes) related to previous studies, we evidenced that the topological factors are of primary importance. ${ }^{1,16,17 b, 39}$ According to the degree of shape anisotropy of solutes (for instance, spheroid, cylinder, spiral,...), the efficiency of global shape recognition mechanisms (which are closely related to steric exclusion effects) is basically different, the best situation being met with a spiral topology rather than a spheroid one.

As shape recognition mechanisms are short-range interactions that are highly active when the solute is in the closest vicinity of the polypeptide, they are strongly dependent on possible local electronic (electrostatic) interactions between the solute and the chiral fiber, and in particular the flexible side chain of the polymer. Hence, the electronic local properties related to the nature of substituents (presence of $\mathrm{HB}$, strength of $\mathrm{C}-\mathrm{O}$ dipole moment, steric hindrance) in combination with the global properties of the analyte (the global dipole moment) play a key role in the solute-PBLG interactions and their capability to "maintain" or not the solute close to the chiral fiber, namely when the CDM are the most efficient.

The role of intermolecular HB. In this series of results, we have evidenced the importance and the role of $\mathrm{HB}$ between the substituent and the PBLG fibers in the mechanisms, in particular when the access of the labile hydrogen is easy. As can be observed in Table 1, solutes $\mathbf{2}$ and $\mathbf{8}$ present the highest degree of discrimination $\left({ }^{13} \mathrm{C} \mathrm{NMR}\right)$ of all the solutes discussed in the present study. Both solutes possess a $\mathrm{COOH}$ moiety with a labile proton susceptible to be engaged in HB with PBLG. Once 2 and 8 are esterified in order to form 6 and 11, respectively, the enantiodiscrimination efficiency is reduced, thus suggesting the importance of the carboxyl proton to interact with PBLG. Moreover, when analyzing cylindrical topologies of series I and II (Table S4, ESI $\dagger$ ), it is observed that, independently of the distorted cylindrical ESP-topology of each of the solutes, $\mathrm{COOH}$ groups in series $\mathbf{2}$ and $\mathbf{8}$ present a proper cavity above the cylindrical ESP form (around $4 \AA$ of diameter) that can promote the access of the PBLG basic moiety in order to "orient" the HB interaction, regardless of the known PBLG's conformational dynamics.

The strength of the C-O dipole moment. When HB is not possible, other electronic factors related to the nature of the Y substituent can play a role, and must be taken into account to understand the NMR results and explain the mechanisms. In particular, the presence of a "C-O" dipole (with an electronegative oxygen atom with accessible lone pairs) can be seen as an important factor enhancing the PBLG-solute interaction. To discuss this point, the local dipolar moment of "C-O" and " $\mathrm{C}=\mathrm{O}$ " bonds in 2, 3, 4 and 6 has been computed by DFT method, and an attempt to correlate NDS (and their magnitude) was performed. The correlation curve $\left(\mu_{\mathrm{C}-\mathrm{O}}\right.$ versus $\%$ of discriminated ${ }^{13} \mathrm{C}$ sites) is plotted in Fig. 9. Regardless of the electrodonor or electro-attractor character of each substituent within the biaryls, the analysis of $\mu_{\mathrm{C}-\mathrm{O}}$ values is informative. Thus, we can notice that the variation of $\mu_{\mathrm{C}-\mathrm{O}}$ trends is rather linear for 2 , 3 and 4 for series I whereas electro-donor (ED)/electro-attractor (EA) properties towards biaryl electronic density differ from each other (EA for 2 and 3, and ED for 4). The divergence observed for 6 (compared to the linearity observed for 2, 3 and 4) is rather surprising because $\mu_{\mathrm{C}-\mathrm{O}}(6)$ is very similar to $\mu_{\mathrm{C}-\mathrm{O}}(2)$. Indeed, for an isovalue of $\mu_{\mathrm{C}-\mathrm{O}}$, we might expect similar NDS. This situation suggests that $\mathrm{HB}$ is the primary driving force of 2 to interact with PBLG. Once no labile proton is available, solute 6 only has the $\mathrm{C}-\mathrm{O}$ dipole as driving force, such as $\mathbf{3}$ and $\mathbf{4}$ in order to interact with PBLG by means of a positive dipole within the mobile arm. This occurrence perfectly illustrates the multivariable dependency of NDS.

Role of $\pi$-stacking. Considering the aromatic character of biaryls and the terminal benzyl of PBLG side chain, the existence of non-covalent $\pi-\pi$ stacking interactions between these rings is a priori possible. Similarly to other interactions already discussed, the latter can also play a role in the CDM (and subsequently in the NDS) by helping to bring the solute closer to the chiral fiber. ${ }^{31}$ Theoretically, the strength of this interaction is primarily dependent on the energy of the highest occupied molecular orbital (HOMO) of the biaryl (located either on the ring A or B), which depends in turns on the activation/deactivation effects of the Y substituents in the rings (series I and II).

From the chemical reactivity viewpoint, it is known that we can relate the Lewis bases (HOMOs with rich electronic density) with the Lewis acids (LUMOs with deficiency in electronic density). ${ }^{40}$ 


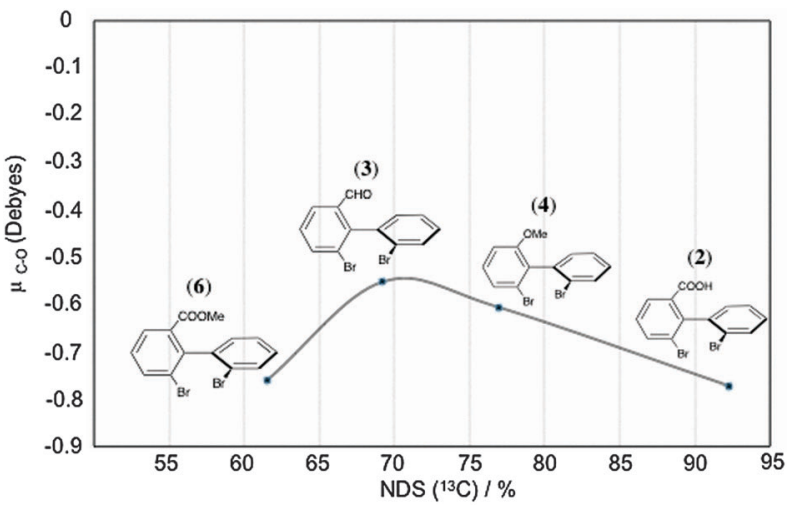

Fig. 9 Variation of the predicted $\mathrm{C}$-O dipole moment (obtained by Mulliken charge distribution analysis, see details in the Experimental Section) as a function of the percentage of $\operatorname{NDS}\left({ }^{13} \mathrm{C}\right)$ for biaryl solutes $(\mathbf{2}, \mathbf{3}, \mathbf{4}$ and $\mathbf{6})$ of series I (see Table 1).

In our case, the $\pi$-stacking interaction (which can be though of as being a specific kind of dipole-dipole interaction $)^{41}$ could also be explained in terms of frontier molecular orbital approach, and hence regarded as a Lewis base (HOMO) interacting with an acidic moiety (LUMO). In this context, dipole-dipole $\pi$-stacking interactions between biaryls (HOMO) and PBLG benzylic rings (LUMO) can be reasonably proposed.

To understand our purpose, we have determined the location and the electronic density charge of HOMOs for six model compounds of the series I $(\mathbf{1}, \mathbf{2}, \mathbf{6})$ and II $(\mathbf{7}, \mathbf{8}, \mathbf{1 1})$, and then correlated both pieces of information with the NDS revealed by ${ }^{13} \mathrm{C}$ NMR. To illustrate our purpose, Fig. 10 proposes such a graphical correlation. As seen in the figure, the resulting effect due to the various activation/deactivation contributions of the three substituents leads to the HOMOs of biaryls being located either on ring $\mathrm{A}(\mathbf{1}, 7)$ or on ring $\mathrm{B}(\mathbf{2}, \mathbf{6}, \mathbf{8}, \mathbf{1 1})$. Note however that the replacement of $\mathrm{Br}$ by $\mathrm{Cl}$ atom on ring $\mathrm{A}$ (series I and II) only slightly modifies the electronic density charge but not the position of the HOMOs on the rings.

Excluding all electronic effects discussed previously and just limiting the discussion to the $\pi$-stacking interaction, a correlation between the $\operatorname{NDS}\left({ }^{13} \mathrm{C}\right)$ and the location of HOMOs, their electronic density charge, and also the steric hindrance on each

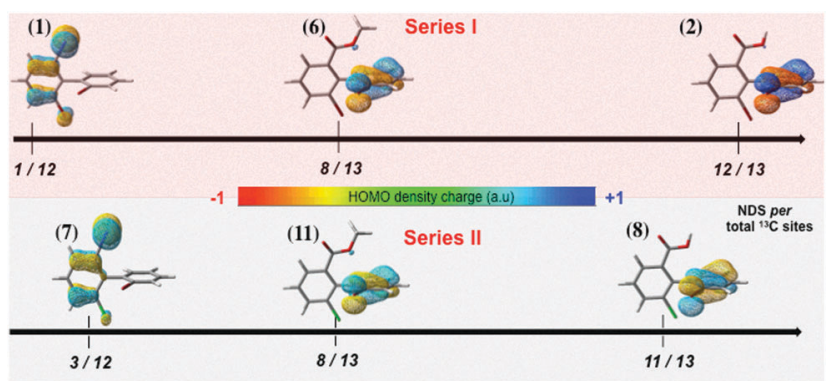

Fig. 10 Representation of the highest occupied molecular orbital electronic densities of some biaryls of series I (red zone) and series II (grey zone). HOMOs were plotted with the same contour levels and their relative charges were normalized for all species at the same conditions. ring (number and size of substituents) can be proposed. Thus, biaryl species $(\mathbf{1}, 7)$ with a Y substituent (I atom) that localizes the electronic density of HOMOs within the di-substituted ring A (1 and 7) present the lowest number of discriminated ${ }^{13} \mathrm{C}$ sites. In contrast, once the $\mathrm{Y}$ group relocalizes the electronic density charge of HOMOs at ring B (mono-substituted), the NDS is considerably enhanced. Besides, $\mathrm{Y}$ groups like $\mathrm{COOH}$ not only re-localize the electronic density charge on ring B, but also increase the electronegativity of HOMOs (observed by negative red HOMO lobes for $\mathrm{COOH}$-dibromide-biaryl solute 2) due to the $\mathrm{COOH}$ 's deactivating nature on ring A. The last could be conceived as if $\mathrm{COOH}$ increases the Lewis basic nature of biaryls and thus increases the "reactivity" towards a Lewis acid (PBLG benzyl ring). Finally, the presence of a lower steric hindrance in ring B (a single mono-atomic ortho-substituent) with respect to ring A (two ortho-substituents with complex dynamics for Y) reinforces the idea that HOMOs at ring B are more susceptible to establishing $\pi$-stacking interactions with the LUMOs of PBLG rings (compared to HOMOs at site A). In other words, ring B is more sterically free to form dipole-dipole $\pi$-stack interactions with PBLG.

Actually, for these six solutes, the variation of NDS can be globally understood as follows. For solutes $\mathbf{2}$ and $\mathbf{8}$, three highly favorable electronic factors enhance the efficiency of CDM (thus leading to a maximal NDS), the presence of $\mathrm{HB}$, the strength of $\mathrm{C}-\mathrm{O}$ dipole and the location of HOMOs at ring B. For solutes 6 and 11, HB is impossible, and only two favorable electronic factors exist (the strength of $\mathrm{C}-\mathrm{O}$ dipole and the location of HOMOs at ring B), thus reducing the efficiency of CDM (and the NDS). For solutes 1 and 7, the absence of important elements ( $\mathrm{HB}$ and $\mathrm{C}-\mathrm{O}$ dipole) on the $\mathrm{Y}$ substituent leads to the less favorable situation with respect to CDM, thus leading to smaller NDS in the series.

The global dipole moment. In a simple interactional model, it seemed reasonable to correlate the experimental $\operatorname{NDS}\left({ }^{13} \mathrm{C}\right)$ and the magnitude of the overall molecular dipole moment $\left(\mu_{\mathrm{mol}}\right)$ of the minimum-energy structure of a solute within a particular solvation media. Experimentally, this univocal correlation does not fully explain the results observed, mainly for two reasons: (i) the specific contribution of local, electronic factors (such as those associated with the Y substituents) as discussed above; and (ii) the too simplified model using a single $\mu_{\text {mol }}$ value associated to the most stable conformer instead of describing the dipole moment distribution (within a dynamic system) as a function of the conformational freedom, e.g. dependent of interring $\phi$ angle. To illustrate this idea, the theoretical variation of $\mu_{\mathrm{mol}}$ by scanning the electronic energy barrier (which can be related to conformational population) of the rings' interplanar angle of two model biaryls, 2 and 5, was obtained (see Fig. S16, ESI $\dagger$ ). In the first case, it is observed that $\mu_{\mathrm{mol}}$ retains roughly constant (variation of $\mu_{\text {mol }}$ versus $\phi$ is below $10 \%$ ) regardless the energetic profile, while in the second one a large variation of the overall $\mu_{\text {mol }}$ versus $f$ (up to two fold) exists. This heterogeneity of distribution illustrates the complexity of the contribution of the nature of the Y substituents to the $\mu_{\mathrm{mol}}$ value. It also points out that the $\mu_{\text {mol }}$ value taking into account the 
conformational distribution should be a more reliable parameter in our attempts to explain the NDS $\left({ }^{13} \mathrm{C}\right)$ with the exclusive basis of the molecular dipole moment.

\section{Conclusions}

New emerging pure enantiomeric structures need robust analytical tools to determine the enantiopurity of a given class of chiral compounds, in particular when routine methods failed or requested instrumentation specific accessories.

The aim of this work was: (i) to propose a panel of simple and robust $1 \mathrm{D} / 2 \mathrm{D}-\mathrm{NMR}$ experiments in CLCs to investigate the chiral biaryls, without any need for NMR expertise, (ii) to present the relevant analytical subtleties to understand all NMR observables in CLCs and their consequences on spectra; and (iii) to analyze and correlate all data to provide new insights into the factors playing a role within the CDMs of polypeptide CLC, thus leading to a better understanding of all interaction mechanisms and enantiorecognition phenomena.

Among the appealing results of the present study, the analysis of NDS and the magnitude of enantiodiscriminations in the ${ }^{13} \mathrm{C}$ NMR spectra revealed the importance of the global molecular shape anisotropy of analytes, the role of (local) electronic properties of substituents (compared to global properties) to maintain the solute in the vicinity of the PBLG fibers and, last but not least, the subtle balance between the electronic effects favoring interaction with PBLG and the steric repulsion associated with the size of substituents.

From the results reported in this work, it appears that NMR in polypeptide CLC should be considered as a valuable tool to analyze the enantiopurity of molecular structures belonging to the fascinating family of (bridged and non-bridged) biaryl atropisomers.

\section{Acknowledgements}

This research work was supported by the CNRS and the MENR. P.L. and F.L. are very much grateful to the CNRS for the continuous financial support of fundamental research. J.-E.H.-P. thanks Labex $\mathrm{CHARM}_{3} \mathrm{AT}$ and V.J. is very grateful to the IFCPAR/CEFIPRA for their postdoctoral fellowship.

\section{References}

1 G. Bringmann, G. Günther, M. Ochse, O. Schupp and S. Tasler, in Progress in the Chemistry of Organic Natural Products, ed. W. Herz, H. Falk, G. W. Kirby, R. E. Moore and C. Tamm, Springer, New York, 2001, vol. 82, p. 1.

2 (a) A. V. R. Rao, M. K. Gurjar, K. L. Reddy and A. S. Rao, Chem. Rev., 1995, 95, 2135; (b) K. C. Nicolaou, C. N. C. Boddy, S. Bräse and N. Winssinger, Angew. Chem., Int. Ed., 1999, 38, 2096; (c) O. Baudoin and F. Guéritte, in Studies in Natural Product Chemistry, ed. Atta-Ur-Rahman, Elsevier, 2003, vol. 29, p. 355; (d) T. Leermann, P. E. Broutin, F. R. Leroux and F. Colobert, Org. Biomol. Chem., 2012, 10, 4095.
3 (a) S. M. Kupchan, R. W. Britton, M. F. Ziegler, C. J. Gilmore, R. J. Restivo and R. F. Bryan, J. Am. Chem. Soc., 1973, 95, 1335; (b) R. W.-J. Wang, L. I. Rebhun and S. M. Kupchan, Cancer Res., 1977, 37, 3071; (c) F. Zavala, D. Guenard, J.-P. Robin and E. Brown, J. Med. Chem., 1980, 23, 546; (d) R. Dhal, E. Brown and J.-P. Robin, Tetrahedron, 1983, 39, 2787; (e) K. Tomioka, T. Ishiguro, H. Mizuguchi, N. Komeshima, K. Koga, S. Tsukagoshi, T. Tsuruo, T. Tashiro, S. Tanida and T. Kishi, J. Med. Chem., 1991, 34, 54; $(f)$ D. B. M. Wickramaratne, T. Pengsuparp, W. Mar, H.-B. Chai, T. E. Chagwedera, C. W. W. Beecher, N. R. Farnsworth, A. D. Kinghorn, J. M. Pezzuto and G. A. Cordell, J. Nat. Prod., 1993, 56, 2083; (g) D. L. Sackett, Pharmacol. Ther., 1993, 59, 163; (h) B. Yalcouye, S. Choppin, A. Panossian, F. R. Leroux and F. Colobert, Eur. J. Org. Chem., 2014, 6285.

4 (a) A. A. Patchett and R. P. Nargund, in Annu. Rep. Med. Chem., ed. G. L. Trainor, Academic Press, New York, 2000, section IV, vol. 35, p. 289; (b) F. Leroux, Curr. Med. Chem., 2005, 12, 1623; (c) F. Leroux, ChemBioChem, 2004, 5, 644; (d) F. Leroux, T. U. Hutschenreuter, C. Charriere, R. Scopelliti and R. W. Hartmann, Helv. Chim. Acta, 2003, 86, 2671; (e) E. Baston and F. R. Leroux, Recent Pat. AntiCancer Drug Discovery, 2007, 2, 31.

5 (a) T. P. Yoon and E. N. Jacobsen, Science, 2003, 299, 1691; (b) M. McCarthy and P. J. Guiry, Tetrahedron, 2001, 57, 3809; (c) R. Noyori, Angew. Chem., Int. Ed., 2002, 41, 2008; (d) T. Hayashi, Acc. Chem. Res., 2000, 33, 354; (e) J. M. Brunel, Chem. Rev., 2005, 105, 857; $(f)$ O. Baudoin, Eur. J. Org. Chem., 2005, 4223; $(g)$ G. Bringmann, A. J. Price Mortimer, P. A. Keller, M. J. Gresser, J. Garner and M. Breuning, Angew. Chem., Int. Ed., 2005, 44, 5384; (h) J. Wencel-Delord, A. Panossian, F. R. Leroux and F. Colobert, Chem. Soc. Rev., 2015, 44, 3418.

6 (a) G. Bringmann, R. Walter and R. Weirich, Angew. Chem., Int. Ed., 1990, 29, 977; (b) M. Putala, Enantiomer, 1999, 4, 243; (c) P. Lloyd-Williams and E. Giralt, Chem. Soc. Rev., 2001, 30, 145; (d) C. Bolm, J. P. Hildebrand, K. Muñiz and N. Hermanns, Angew. Chem., 2001, 113, 3382; (e) Angew. Chem., Int. Ed., 2001, 40, 3284; $(f)$ J. Hassan, M. Sévignon, C. Gozzi, E. Schultz and M. Lemaire, Chem. Rev., 2002, 102, 1359.

7 A. Ahmed, R. A. Bragg, J. Clayden, L. W. Lai, C. McCarthy, J. H. Pink, N. Westlund and S. A. Yasin, Tetrahedron, 1998, 54, 13277.

8 F. R. Leroux, A. Berthelot, L. Bonnafoux, A. Panossian and F. Colobert, Chem. - Eur. J., 2012, 18, 14232.

9 (a) J. Graff, T. Debande, J. Praz, L. Guenee and A. Alexakis, Org. Lett., 2013, 15, 4270; (b) Q. Perron and A. Alexakis, Adv. Synth. Catal., 2010, 352, 2611.

10 (a) K. Kabuto, F. Yasuhara and S. Yamaguchi, Tetrahedron Lett., 1980, 21, 307; (b) K. Kabuto, F. Yasuhara and S. Yamaguchi, Tetrahedron Lett., 1981, 22, 659; (c) A. Alexakis, J. C. Frutos and P. Mangeney, Tetrahedron Lett., 1994, 35, 5125.

11 M. Sarfati, P. Lesot, D. Merlet and J. Courtieu, Chem. Commun., 2000, 2069.

12 (a) C. Aroulanda, D. Merlet, J. Courtieu and P. Lesot, J. Am. Chem. Soc., 2001, 123, 12059; (b) P. Lesot, Z. Luz, 
C. Aroulanda and H. Zimmermann, Magn. Reson. Chem., 2014, 52, 581.

13 P. Lesot, C. Aroulanda, H. Zimmerman and Z. Luz, Chem. Soc. Rev., 2015, 44, 2330.

14 (a) P. Lesot, O. Lafon, H. B. Kagan and P. Fan, Chem. Commun., 2006, 389; (b) O. Lafon, P. Lesot, C. A. Fan and H. B. Kagan, Chem. - Eur. J., 2007, 13, 3772.

15 (a) T. Wenzel, Discrimination of Chiral Compounds using NMR Spectroscopy, John Wiley \& Sons, INC publication, Wiley-Interscience, 2007; (b) T. J. Wenzel and C. D. Chisholm, Prog. Nucl. Magn. Reson. Spectrosc., 2011, 59, 1; (c) T. J. Wenzel and C. D. Chisholm, Chirality, 2011, 23, 190; (d) S. R. Chaudhari and N. Suryaprakash, J. Indian Inst. Sci., 2014, 94(4), 485.

16 (a) A. Meddour, P. Berdagué, A. Hedli, J. Courtieu and P. Lesot, J. Am. Chem. Soc., 1997, 119, 4502; (b) P. Lesot, O. Lafon, J. Courtieu and P. Berdagué, Chem. - Eur. J., 2004, 10, 3741; (c) P. Tzvetkova, B. Luy and S. Simova, in Topics in Chemistry and Material Science 5, Current Issues in Organic Chemistry, ed. R. D. Nikolova, S. Simova, P. Denkova and G. N. Vayssilov, Heron Press Ltd, Birmingham, 2011, pp. 70-77.

17 (a) P. Lesot, D. Merlet, A. Loewenstein and J. Courtieu, Tetrahedron: Asymmetry, 1998, 9, 1871; (b) P. Lesot, M. Sarfati and J. Courtieu, Chem. - Eur. J., 2003, 9, 1724; (c) P. Lesot and J. Courtieu, Prog. Nucl. Magn. Reson. Spectrosc., 2009, 55, 128; (d) P. Lesot, In Deuterium NMR of Liquid-Crystalline Samples at Natural Abundance, eMagRes, 2013, 2(3), 315, DOI: 10.1002/9780470034590.Emrstm1318.

18 L. Bonnafoux, F. R. Leroux and F. Colobert, Beilstein J. Org. Chem., 2011, 7, 1278.

19 L. Bonnafoux, R. Gramage-Doria, F. Colobert and F. R. Leroux, Chem. - Eur. J., 2011, 17, 11008.

20 (a) C. Aroulanda, M. Sarfati, J. Courtieu and P. Lesot, Enantiomer, 2001, 6, 281; (b) C. M. Thiele and S. Berger, Org. Lett., 2003, 5, 705; (c) P. Lesot, O. Lafon, C. Aroulanda and R. Dong, Chem. - Eur. J., 2008, 14, 4082.

21 H. Kovacs, D. Moskau and M. Spraul, Prog. Nucl. Magn. Reson. Spectrosc., 2005, 46, 131.

22 M. J. Frisch, et al., Gaussian 09, Revision D.01, Gaussian, Inc., Wallingford CT, 2009.

23 (a) J. Tomasi, R. Cammi, B. Mennucci, C. Cappelli and S. Corni, Phys. Chem. Chem. Phys., 2002, 4, 5697; (b) J. Tomasi, B. Mennucci and R. Cammi, Chem. Rev., 2005, 105, 2999.

24 A. D. Becke, J. Chem. Phys., 1993, 98, 5648.
25 C. T. Lee, W. T. Yang and R. G. Parr, Phys. Rev. B: Condens. Matter Mater. Phys., 1988, 37, 785.

26 P. J. Hay and W. R. Wadt, J. Chem. Phys., 1985, 82, 299.

27 C. Canlet, D. Merlet, P. Lesot, A. Meddour, A. Loewenstein and J. Courtieu, Tetrahedron: Asymmetry, 2000, 11, 1911.

28 L. Bonnafoux, L. Ernst, F. R. Leroux and F. Colobert, Eur. J. Inorg. Chem., 2011, 3387.

29 A. Meddour, J. Uziel, J. Courtieu and S. Jugé, Tetrahedron: Asymmetry, 2006, 17, 1424.

30 A. M. Marathias, P. A. Tate, N. Papaioannou and W. Massefski, Chirality, 2010, 22, 838.

31 (a) E. E. Burnell and C. A. De Lange, Chem. Rev., 1998, 98, 2359; (b) E. E. Burnell and C. A. De Lange, NMR of Ordered Liquids, Kluwer, Academic, Dordrecht, 2003, ch. 10 to 14 included.

32 (a) A. Enthart, J. C. Freudenberger, J. Furrer, H. Kessler and B. Luy, J. Magn. Reson., 2008, 192, 314; (b) T. Reinsperger and B. Luy, J. Magn. Reson., 2014, 239, 110.

33 G. A. Morris, in Two-Dimensional J-Resolved 2D Spectroscopy, Encyclopedia of Magnetic Resonance, ed. R. K. Harris and R. E. Wasylishen, Wiley, Chichester, 2009, DOI: 10.1002/ 9780470034590.emrstm0579.pub2.

34 (a) J. R. Garbow, D. P. Weitekamp and A. Pines, Chem. Phys. Lett., 1982, 93, 504; (b) A. Bax, J. Magn. Reson., 1983, 53, 517; (c) A. Lupulescu, G. L Olsen and L. Frydman, J. Magn. Reson., 2013, 218, 141.

35 (a) G. A. Morris and R. Freeman, J. Am. Chem. Soc., 1979, 101, 760; (b) D. M. Doddrell, D. T. Pegg and M. R. Bendall, J. Magn. Reson., 1982, 48, 323; (c) G. A. Morris, J. Am. Chem. Soc., 1980, 102, 428.

36 H. O. Kalinowski, S. Berger and S. Braun, Carbon-13 NMR Spectroscopy, J. Wiley and Sons, Chichester, 1984.

37 (a) A. Bax, R. Freeman and S. P. Kempsell, J. Am. Chem. Soc., 1980, 102, 4849; (b) A. Bax, R. Freeman, T. A. Frenkiel and M. H. Levitt, J. Magn. Reson., 1981, 43, 478; (c) P. Lesot, J. W. Emsley and J. Courtieu, Liq. Cryst., 1998, 25, 123.

38 J. W. Emsley, P. Lesot and D. Merlet, Phys. Chem. Chem. Phys., 2004, 6, 522.

39 P. Lesot, Z. Serhan, C. Aroulanda and I. Billault, Magn. Reson. Chem., 2012, 50, S2.

40 K. Fukui, T. Yonezawa and H. Shingu, J. Chem. Phys., 1952, 20, 722 .

41 C. A. Hunter and J. K. M. Sanders, J. Am. Chem. Soc., 1990, $112,5525$. 